\title{
TERRITORIALIDAD DE LOS DERECHOS DE AUTOR Y MERCADO ÚNICO DIGITAL
}

\section{DIGITAL SINGLE MARKET AND TERRITORIALITY OF COPYRIGHT}

\author{
Pedro Alberto de Miguel Asensio \\ Catedrático de Derecho internacional privado \\ Universidad Complutense de Madrid
}

Recibido: 12.06.2020 / Aceptado: 01.07.2020

DOI: https://doi.org/10.20318/cdt.2020.5613

\begin{abstract}
Resumen: Un rasgo distintivo de la UE es el nivel particularmente elevado de armonización de los regímenes nacionales de derecho de autor, lo que puede facilitar el desarrollo de mecanismos específicos para sortear la actual fragmentación del mercado interior al margen de la creación de títulos unitarios. El alcance de la competencia judicial internacional condiciona la adopción de medidas judiciales para la tutela de derechos de autor en diversos Estados miembros, pero tal posibilidad requiere la aplicación de tantas legislaciones como Estados. En algunos instrumentos recientes se observa una tendencia renovada a recurrir al criterio del país de origen para superar obstáculos derivados de los regímenes nacionales de derecho de autor. En este contexto, se valoran las aportaciones del Reglamento (UE) 2017/1128 y las Directivas (UE) 2019/789 y 2019/790 en lo relativo a la regulación de las actividades transfronterizas en el marco del mercado único digital.
\end{abstract}

Palabras clave: propiedad intelectual, Unión Europea, Internet, competencia judicial, derecho aplicable.

Abstract: A distinctive feature of the EU is the particularly high level of harmonisation of the national copyright regimes. This may facilitate the adoption of specific mechanisms to get around the current fragmentation within the internal market in the absence of a single EU copyright title. Enforcement measures based on national rights are limited to the territory of the respective rights, although the possibility to adopt measures with respect to the Union or several Member States depends, first of all, on the extent of the jurisdiction granted to national courts. A renewed trend to have recourse to the country of origin principle to overcome some of the obstacles posed to the digital single market by the national copyright regimes can be found in some recent instruments. Regulation (UE) 2017/1128 and Directives (EU) 2019/789 and 2019/790 are discussed with a particular focus on their impact on crossborder activities.

Keywords: copyright and related rights, European Unión, Internet, jurisdiction, choice of law.

Sumario: I. Introducción. II. Fragmentación de la propiedad intelectual y funcionamiento del mercado interior. III. ¿Hacia el establecimiento de títulos unitarios? IV. Tutela transfronteriza de los derechos de autor. 1. Fundamentos. 2. Correlación entre competencia judicial y territorialidad de la propiedad intelectual. 3. Límites y condicionantes de la competencia de alcance global. V. Fundamento y retos del criterio lex loci protectionis. VI. Mercado interior y aplicación de un régimen unitario. 1. El criterio de origen en el entorno digital. 2. Portabilidad transfronteriza de contenidos en línea. 3. Directiva (UE) 2019/790 sobre los derechos de autor en el mercado único digital. 4. Transmisiones en línea de organismos de radiodifusión. VII. Perspectivas de futuro. 


\section{Introducción}

1. Entre la esencia del mercado único en el seno de la Unión Europea y el carácter estrictamente nacional de los derechos de autor y derechos conexos que coexisten en la Unión cabe apreciar una abierta contradicción, que condiciona la circulación, explotación y tutela de contenidos creativos en la UE. Esa oposición y los obstáculos que de la territorialidad de los derechos de propiedad intelectual derivan para el desarrollo de actividades en línea transfronterizas en la Unión han sido destacados de manera reiterada por la Comisión Europea como uno de los aspectos que debe ser superado en sus iniciativas de desarrollo del mercado único digital en materia de derechos de autor y derechos conexos. La Comisión vincula las dificultades que encuentra la posibilidad de hacer cumplir de forma efectiva los derechos de autor a nivel de la Unión y los obstáculos al uso transfronterizo de los contenidos protegidos por esos derechos en el mercado único digital con la circunstancia de que todos estos derechos "siguen siendo territoriales", de modo que no existe un único título de derechos de autor válido en el conjunto de la UE sino tantos títulos nacionales diferentes como Estados miembros ${ }^{1}$.

2. En realidad, la contradicción con el mercado único no deriva de la territorialidad, rasgo inherente a los derechos de autor y derechos conexos, sino precisamente de la coexistencia en la Unión de títulos de carácter nacional. La diferencia entre un título nacional y otro unitario -que sí existe en otros ámbitos, como las marcas, diseños o indicaciones geográficas- no es el carácter territorial de los derechos, ya que todos lo son, sino su alcance; mientras que los primeros se limitan al territorio de cada Estado miembro, los títulos unitarios van referidos al territorio del conjunto de la Unión ${ }^{2}$. La Comisión ha insistido en que la construcción del mercado único, la prosperidad de la economía europea y la libre circulación de los contenidos científicos y culturales exigen la creación en el futuro de títulos únicos y normativas únicas para el conjunto de la Unión que superen las actuales particularidades de los títulos de derecho de autor nacionales de los Estados miembros. Incluso ha llegado a poner de relieve que la adopción "de un código de derechos de autor único y de un único título de derechos de autor exigiría" (para garantizar su aplicación uniforme) "una única jurisdicción competente sobre los derechos de autor, con su propio tribunal, de modo que una jurisprudencia incoherente no contribuya a una mayor fragmentación"3.

3. Ahora bien, el establecimiento de títulos en materia de derechos de autor y derechos conexos que tengan carácter unitario y produzcan los mismos efectos en todo el territorio de la Unión, de modo que su explotación y protección sea posible para el conjunto de la Unión con base en una normativa común, constituye únicamente una visión de la Comisión como objetivo a largo plazo (apdo. III, infra). Por consiguiente, no cabe renunciar a valorar el potencial de otras alternativas, que sin suponer una transformación tan radical del actual entramado normativo puedan contribuir a facilitar la tutela y explotación transfronterizas de los productos culturales en el conjunto del mercado único y permitir de manera eficaz hacer frente a las dificultades derivadas de la fragmentación inherente a la coexistencia de tantos títulos independientes como Estados miembros.

4. La tutela civil de estos derechos más allá del territorio de un Estado miembro se halla condicionada por las posibilidades de su titular de reclamar dicha tutela conforme a las normas de competencia judicial internacional. Si bien la unificación de las normas sobre cooperación judicial civil en el seno de la Unión ha ido unida a la consolidación de criterios de competencia que hacen posible la tutela transfronteriza de esos derechos, incluido en su caso el ejercicio de acciones relativas a la tutela de derechos de autor de Estados miembros diversos ante un único tribunal (apdo. IV, infra), la fragmentación

\footnotetext{
${ }^{1}$ Comunicación de la Comisión: Hacia un marco moderno y más europeo de los derechos de autor, COM(2015) 626 final, 9 de diciembre de 2015, pp. 3-4.

2 Vid., v,gr., J. DrexL, "Internationales Immaterialgüterrecht", Münchener Kommentar zum Bürgerlichen Gesetzbuch, 7th ed., Bd. 12, Munich, C.H. Beck, 2018, pp. 1241-1405, para. 133.

${ }^{3}$ Comunicación de la Comisión: Hacia un marco moderno... cit., p. 14.
} 
resultante del carácter nacional de los títulos excluye en la práctica la posibilidad de adoptar medidas relativas al territorio de la Unión con base en una única legislación (apdo. V, infra). Al margen de la eventual creación futura de títulos unitarios, cabe apreciar que si bien los instrumentos normativos adoptados en el marco del mercado único digital dejan inalteradas las normas sobre Derecho internacional privado, sí contemplan la introducción de mecanismos específicos tendentes a facilitar la aplicación de una única normativa en situaciones conectadas con varios Estados miembros, en particular mediante la extensión del llamado criterio del país de origen con respecto a ciertas actividades en línea, así como otros mecanismos basados en la localización ficticia en un único Estado miembro de actos de utilización en línea de contenidos (apdo. VI, infra).

\section{Fragmentación de la propiedad intelectual y funcionamiento del mercado interior}

5. Como el propio Tribunal de Justicia ha destacado, el principio de territorialidad de los derechos de autor y derechos afines es un principio reconocido por el Derecho internacional y admitido igualmente por el Derecho de la Unión, de modo que tales derechos tienen necesariamente carácter territorial y cada legislación nacional únicamente puede sancionar actos que tengan lugar en su respectivo territorio nacional ${ }^{4}$. Cuando una obra goza de protección en múltiples Estados su titular se ve atribuido un conjunto de derechos diferenciados que recaen sobre un mismo objeto pero van referidos a territorios diferentes ${ }^{5}$. Consecuencia de la independencia de los sistemas nacionales es que el contenido de la propiedad intelectual -los derechos de carácter patrimonial y personal que la integran así como los límites y excepciones a los mismos- sobre una misma creación varía según los países, sin perjuicio de que tales derechos se atribuyan ex lege al margen de cualquier formalidad, frente a lo que es habitual en el caso de los derechos de propiedad industrial, así como que el alcance de la armonización internacional y europea en la materia tienden a reducir esa disparidad. La independencia de los sistemas nacionales determina también que quién tiene atribuida en un determinado momento la titularidad de algunos de esos derechos sobre una misma creación pueda variar según los países.

6. Incluso en el seno de la UE el importante logro que representan las numerosas directivas relativas a la armonización de los derechos de autor y derechos afines adoptadas en los últimos lustros no ha alterado la situación de que tales derechos se hallan circunscritos al territorio de cada uno de los Estados miembros, tanto en lo relativo a su existencia como a sus efectos ${ }^{6}$. Si bien las directivas de armonización exigen la protección de los derechos de autor de modo automático en todos los Estados miembros, tales derechos, como consecuencia de su carácter nacional y del principio de territorialidad, únicamente pueden ser infringidos "respectivamente, en cada uno de los Estados miembros, en función del Derecho sustantivo aplicable"7. La territorialidad nacional inherente a estos derechos ha condicionado también su exclusión de ciertas normas esenciales en relación con el funcionamiento del mercado interior con respecto a la utilización y explotación de contenidos en línea, como es el caso del criterio de origen establecido en el artículo 3 de la Directiva 2000/31 sobre el comercio electrónico ${ }^{8}$.

7. El que la coexistencia en el seno de la Unión de derechos de propiedad intelectual de carácter nacional puede repercutir negativamente en el funcionamiento del mercado interior $\mathrm{y}$, en particular, me-

\footnotetext{
${ }^{4}$ STJUE de 14 de julio de 2005, Lagardère, C-192/04, EU:C:2005:475, apdo. 46.

5 A. Peukert, "Territoriality and Extraterritoriality in Intellectual Property Law", G. Handl, J. Zekoll \& P. Zumbansen (eds.), Beyond Territoriality: Transnational Legal Authority in an Age of Globalization, Brill, Leiden/Boston, 2012, 189-228, http://ssrn.com/abstract\%3D1592263, apdo. I.A.

${ }^{6}$ Vid., v.gr., Conclusiones del AG Jääskinen de 13 de junio de 2013, Pinckney, C-170/12, EU:C:2013:400, apdo. 48.

${ }^{7}$ STJUE de 22 de enero de 2015, Hejduk, C-441/13, EU:C:2015:28, apdo. 22, con referencia a la STJUE de 3 de octubre de 2013, Pinckney, C-170/12, EU:C:2013:635, apdo. 39.

${ }^{8}$ Directiva 2000/31/CE, de 8 de junio de 2000, relativa a determinados aspectos jurídicos de los servicios de la sociedad de la información, en particular el comercio electrónico en el mercado interior (Directiva sobre el comercio electrónico), DO L 178, 17.7.2000, p. 1 .
} 
noscabar la libre circulación de mercancías y servicios ha sido un elemento relevante desde los orígenes de la integración europea. El artículo 36 TFUE reconoce que los derechos de propiedad intelectual pueden justificar prohibiciones o restricciones a la libre circulación de bienes. No obstante, desde hace décadas el Tribunal de Justicia ha venido afirmando que si bien los tratados constitutivos no afectan a la existencia de los derechos de autor y derechos afines reconocidos por la legislación de cada Estado miembro, el ejercicio de tales derechos puede estar sujeto a las restricciones establecidas por el Derecho de la Unión, en particular, las tendentes a evitar una excesiva e injustificada compartimentación territorial del mercado9.

8. Ciertamente, resulta muy significativa a este respecto la consolidación del criterio del agotamiento comunitario con respecto a los derechos de propiedad industrial e intelectual, que tiene claro reflejo en los instrumentos legislativos de la Unión en materia de derechos de autor y derechos afines. Así lo ilustran, por ejemplo, el artículo 4.2 de la Directiva 2001/29/CE sobre los derechos de autor y derechos afines en la sociedad de la información ${ }^{10} \mathrm{o}$ el artículo 4.2 de la Directiva sobre programas de ordenador $^{11}$. Además, el marco resultante de las directivas excluye la posibilidad de que los Estados miembros establezcan que el agotamiento tiene alcance internacional de modo que abarque productos comercializados en terceros países. El alcance territorial del agotamiento de los derechos queda establecido en todo caso por el Derecho de la Unión y se limita a las situaciones en las que los productos se comercializan en el Espacio Económico Europeo ${ }^{12}$. La relevancia práctica del agotamiento con respecto a la explotación en línea de productos culturales se halla condicionada por la circunstancia de que la Directiva 2001/29 se basa en la distinción entre la distribución electrónica y la distribución material de contenidos protegidos, limitando el agotamiento a esta última. En consecuencia, la comercialización en línea mediante descarga de un libro electrónico constituye típicamente un acto de comunicación al público, por lo tanto comprendido en el ámbito del derecho regulado en el artículo 3 de la Directiva 2001/29 (y el art. 20 LPI en España) y excluido del agotamiento ${ }^{13}$. Como excepción, en el caso particular de los programas de ordenador sí resulta de su régimen específico contenido en la Directiva 2009/24 una asimilación entre las copias materiales e inmateriales que determina que el agotamiento del derecho de distribución previsto en su artículo 4.2 abarque la venta de ambos tipo de copias ${ }^{14}$.

9. El importante acervo legislativo de la Unión en materia de derechos de autor y derechos afines está integrado básicamente en un elevado número de directivas de armonización, referidas típicamente a la regulación de aspectos concretos relativos al objeto de protección o al contenido de los derechos ${ }^{15}$. En el ámbito digital, más allá de las Directivas sobre programas de ordenador, ya mencionada, y sobre bases de datos ${ }^{16}$, destacan las Directivas sobre obras huérfanas ${ }^{17}$, licencias multiterritoriales ${ }^{18}$ y transmisiones en línea de los organismos de radiodifusión ${ }^{19}$, si bien los dos instrumentos más importantes son la ya

\footnotetext{
9 Vid., v.gr., STJUE de 8 de junio de 1971, Deutsche Grammophon/Metro SB, C-78/70, EU:C:1971:59, apdos. 11-12.

${ }^{10}$ Directiva 2001/29/CE, de 22 de mayo de 2001, relativa a la armonización de determinados aspectos de los derechos de autor y derechos afines a los derechos de autor en la sociedad de la información, DO L 167, 22.6.2001, p. 10.

${ }^{11}$ Directiva 2009/24/CE, de 23 de abril de 2009, sobre la protección jurídica de programas de ordenador (versión codificada), DO L 111, 5.5.2009, p. 16.

${ }_{12}$ Vid., aunque referidas a derechos de marca, STJUE de 16 de julio de 1998, Silhouette, C-355/96, EU:C:1998:374, apdo. 26; y STJUE de 20 de noviembre de 2001, Zino Davidoff y Levi Strauss, C-414/99, EU:C:2001:617, apdos. 32-33.

${ }^{13}$ STJUE de 19 de diciembre de 2019, Nederlands Uitgeversverbond, C-263/18, EU:C:2019:1111, apdo. 72.

${ }^{14}$ STJUE de 3 de julio de 2012, UsedSoft, C-128/11, EU:C:2012:407, apdos. 58 y 59; y STJUE de 12 de octubre de 2016, Ranks y Vasilevičs, C-166/15, EU:C:2016:762, apdos. 52 a 56.

${ }^{15}$ H. Sснаск, Urheber- und Urhebervertragsrecht, $7^{\mathrm{a}}$ ed., Tübingen, Mohr Siebeck, 2015, pp. 87-88.

${ }_{16}$ Directiva 96/9/CE, de 11 de marzo de 1996, sobre la protección jurídica de las bases de datos, DO L 77 de 27.3.1996, p. 20.

17 Directiva 2012/28/UE, de 25 de octubre de 2012, sobre ciertos usos autorizados de las obras huérfanas, DO L 299 de 27.10.2012, p. 5.

${ }^{18}$ Directiva 2014/26/UE, de 26 de febrero de 2014, relativa a la gestión colectiva de los derechos de autor y derechos afines y a la concesión de licencias multiterritoriales de derechos sobre obras musicales para su utilización en línea en el mercado interior, DO L 84 de 20.3.2014, p. 72.

${ }^{19}$ Directiva (UE) 2019/789, de 17 de abril de 2019, por la que se establecen normas sobre el ejercicio de los derechos de autor y derechos afines aplicables a determinadas transmisiones en línea de los organismos de radiodifusión y a las retransmisiones de programas de radio y televisión, y por la que se modifica la Directiva 93/83/CEE, DO L 130 de 17.5.2019, p. 82.
} 
mencionada Directiva 2001/29, que además procedió a dar cumplimiento a obligaciones internacionales establecidas en los Tratados de la OMPI sobre derechos de autor y sobre interpretación o ejecución y fonogramas, que habían sido adoptados en diciembre de 1996, junto con la reciente Directiva 2019/790, cuyo plazo de transposición se extiende hasta el 7 de junio de $2021^{20}$. Como excepción en lo relativo al tipo de instrumento utilizado, cabe hacer referencia al Reglamento (UE) 2017/1128 sobre portabilidad transfronteriza de los servicios de contenidos en línea ${ }^{21}$ y al Reglamento (UE) 2017/1563 por el que se aplica el Tratado de Marrakech para facilitar el acceso a las obras a las personas con discapacidad visual ${ }^{22}$.

10. El conjunto de directivas adoptadas en el ámbito de los derechos de autor y derechos afines, unido a la importante labor jurisprudencial del Tribunal de Justicia en este sector, proporciona tan solo una armonización fragmentaria y parcial, que dista de constituir una regulación sistemática y completa de la propiedad intelectual ${ }^{23}$. Pese al avance que representa la Directiva 2019/790, la armonización existente presenta significativas carencias, como refleja el régimen de excepciones y limitaciones establecido en el artículo 5 de la Directiva 2001/29, cuyo carácter básicamente facultativo para los Estados facilita la persistencia de diferencias significativas entre los Estados miembros. Esta conclusión no resulta alterada por la circunstancia de que la libertad de los Estados miembros para establecer o no en su legislación las excepción facultativas - como la de copia privada- en la Directiva 2001/29 va unida a la exigencia de que en la medida en que cualquiera de esas excepciones aparece prevista en el ordenamiento de un Estado miembro resulta preciso que respete los condicionantes impuestos por el Derecho de la Unión en lo relativo a la configuración de la excepción de que se trata; por ejemplo, en el caso de la copia privada, con respecto a la concreción del concepto de compensación equitativa ${ }^{24} \mathrm{o}$ acerca de que sea lícita la fuente a partir de la que se realiza una reproducción para uso privado como presupuesto para que la excepción sea aplicable ${ }^{25}$.

11. Si bien la armonización mediante directivas y la jurisprudencia del Tribunal de Justicia relativa a su interpretación uniforme contribuyen a reducir la disparidad resultante de la coexistencia de tantos sistemas nacionales en esta materia como Estados miembros, resulta igualmente claro que no conducen a la aplicación de un régimen unitario a esos derechos ni a la superación de su carácter de títulos estrictamente nacionales ${ }^{26}$. En consecuencia, no es posible obtener la tutela respecto de la infracción de productos intelectuales o culturales en el entorno digital con base en la aplicación de una única legislación con respecto al territorio del conjunto de la Unión.

\section{III. ¿Hacia el establecimiento de títulos unitarios?}

12. Ha quedado ya apuntado cómo uno de los elementos de la modernización de los derechos de autor y derechos afines que la Comisión Europea contempla es la eventual creación a largo plazo de títulos únicos de derechos de autor válidos en todo el territorio de la UE. La unificación de los derechos de autor mediante un régimen unitario referido al conjunto de la Unión ha sido planteada por la Comi-

${ }^{20}$ Directiva (UE) 2019/790, de 17 de abril de 2019, sobre los derechos de autor y derechos afines en el mercado único digital y por la que se modifican las Directivas 96/9/CE y 2001/29/CE, DO L 130 de 17.5.2019, p. 92.

${ }^{21}$ Reglamento (UE) 2017/1128, de 14 de junio de 2017, relativo a la portabilidad transfronteriza de los servicios de contenidos en línea en el mercado interior, DO L 168 de 30.6.2017, p. 1.

${ }^{22}$ Reglamento (UE) 2017/1563, de 13 de septiembre de 2017, sobre el intercambio transfronterizo entre la Unión y terceros países de ejemplares en formato accesible de determinadas obras y otras prestaciones protegidas por derechos de autor y derechos afines en favor de personas ciegas, con discapacidad visual o con otras dificultades para acceder a textos impresos, DO L 242 de 20.9.2017, p. 1.

${ }^{23}$ Vid., v.gr., M.P. CÁmara Águila e I. Garrote Fernández Díez (coords.), La Unificación del Derecho de Propiedad Intelectual en la Unión Europea, Valencia, Tirant lo Blanch, 2019; y E. Rosatı, Copyright and the Court of Justice of the European Union, Oxford, OUP, 2019.

${ }^{24}$ Vid., v.gr., STJUE de 21 de octubre de 2010, Padawan, C-467/08, EU:C:2010:620, apdo. 36.

${ }^{25}$ STJUE de 10 de abril de 2014, ACI Adam BV, C-435/12, EU:C:2014:254, apdo. 35.

${ }^{26}$ H. SСHACK, Urheber... cit., pp. 80-84. 
sión en diversas ocasiones como un objetivo deseable ${ }^{27}$, al tiempo que apoyada en círculos académicos ${ }^{28}$. Ahora bien, 1 margen de esas propuestas, la realidad es que los diversos instrumentos adoptados en el contexto del establecimiento del mercado único digital se limitan básicamente a continuar con la práctica previa de proceder a una aproximación fragmentaria de las legislación sobre derechos autor de los Estados miembros, sin contemplar en ningún caso la creación de títulos unitarios de alcance supranacional. La reciente Directiva 2019/790 resulta ilustrativa a este respecto.

13. La adopción por la UE de medidas relativas a la creación de títulos europeos que garanticen una protección uniforme de los derechos de autor y derechos conexos en el conjunto de la Unión, como permite el artículo 118 TFUE, continúa siendo una mera posibilidad futura sin ninguna propuesta definida acerca de cuál sería su configuración. Ni siquiera se ha precisado si su carácter sería meramente facultativo, en el sentido de representar una simple alternativa a la protección a nivel nacional, o si, por el contrario, reemplazaría a las legislaciones nacionales en la materia e implicaría la desaparición de los títulos nacionales.

14. La ausencia de definición de esta visión a largo plazo se proyecta también en lo relativo a los mecanismos para asegurar la tutela efectiva de esos derechos unitarios en el territorio de la Unión. En el marco de la Estrategia para el Mercado Único Digital, la Comisión ha insistido en que su objetivo a largo plazo es la creación de un título único y por lo tanto de un derecho de autor unitario para el conjunto de la Unión, para poner fin a la fragmentación actual. Resulta llamativo que entre los pocos elementos de concreción propuestos a ese respecto por la Comisión, se encuentre este planteamiento:

"La plena armonización de los derechos de autor en la UE, en la forma de un código de derechos de autor único y de un único título de derechos de autor, exigiría cambios sustanciales en el funcionamiento actual de la normativa. Tendrían que armonizarse ámbitos que hasta el momento se han dejado a la discreción de los legisladores nacionales. La aplicación uniforme de la normativa exigiría una única jurisdicción competente sobre los derechos de autor, con su propio tribunal, de modo que una jurisprudencia incoherente no contribuya a una mayor fragmentación". ${ }^{29}$

15. El criterio de que la creación de títulos unitarios de derecho de autor requiere el establecimiento de una jurisdicción diferenciada con su propio tribunal parece condicionado por la evolución en el ámbito de las patentes y el establecimiento del Tribunal Unificado de Patentes (TUP) ${ }^{30}$. Ahora bien, la creación de títulos unitarios en relación con otros derechos de propiedad industrial ha seguido un modelo diferente, como ilustran el Reglamento sobre la marca de la Unión (RMUE) ${ }^{31}$, el Reglamento sobre el diseño comunitario (RDC) $)^{32}$ y el Reglamento sobre obtenciones vegetales ${ }^{33}$. Estos instrumentos

${ }^{27}$ Creative Content in a European Digital Single Market: Challenges for the Future (A Reflection Document of DG INFSO and DG MARKT), 22 de octubre de 2009, http://ec.europa.eu/internal_market/consultations/docs/2009/content_online/ reflection_paper\%20web_en.pdf, p. 18; Comunicación de la Comisión: Un mercado único de los derechos de propiedad intelectual_Estimular la creatividad y la innovación para generar crecimiento económico, empleos de calidad y productos y servicios de excelencia en Europa, $\operatorname{COM(2011)~} 287$ final, de 24 de mayo de 2011, p. 14, con referencia al futuro análisis de la "la viabilidad de crear un título «unitario» optativo de derechos de autor sobre la base del artículo 118 del TFEU"; y Libro Verde sobre la distribución en línea de obras audiovisuales en la Unión Europea: oportunidades y problemas en el avance hacia un mercado único digital, $\operatorname{COM(2011)~} 427$ final, de 13 de julio de 2011, pp. 14-15.

${ }^{28}$ H. SCHACK, “Europäische Urheberrechts-Verordnung: erwünscht oder unvermeidlich?”, M. LeISTNER (ed.), Europäische Perspektiven des Geistigen Eigentums, Tübingen, Mohr Siebeck, 2010, pp. 173-189, esp. pp. 184-189; y EuROPEAN COPYRIGHT Society, "Letter to Mr Günther Oettinger, Commissioner for Digital Economy and Society, European Commission, on the Unification of Copyright Law (19 December 2014)", https://europeancopyrightsocietydotorg.files.wordpress.com/2015/12/ ecs_letter_to_oettinger_fin-1.pdf.

${ }^{29}$ Comunicación de la Comisión: Hacia un marco moderno y más europeo de los derechos de autor, COM(2015) 626 final, 9 de diciembre de 2015, p. 14.

${ }^{30}$ Acuerdo sobre un tribunal unificado de patentes, DO C 175, 20.6.2013, p. 1, pendiente todavía de entrada en vigor.

${ }^{31}$ Reglamento (UE) 2017/1001, de 14 de junio de 2017, sobre la marca de la Unión Europea, DO L 154, 16.6.2017, p. 1

${ }^{32}$ Reglamento (CE) 6/2002, de 12 de diciembre de 2001, sobre el diseño comunitario, DO L 3, 5.1.2002, p. 1.

${ }^{33}$ Reglamento (CE) 2100/94, de 27 de julio de 1994, relativo a la protección comunitaria de las obtenciones vegetales, DO L 227, 1.9.1994, p. 1. 
atribuyen el conocimiento de las acciones judiciales relativas a la tutela de esos derecho a tribunales nacionales, si bien requieren que los Estados miembros designen en sus territorios un número tan limitado como sea posible de tribunales nacionales de primera y de segunda instancia, encargados de desempeñar las funciones que les atribuyen esos reglamentos. Se trata de un modelo que en principio parece más adecuado que el establecimiento de única jurisdicción competente con su propio tribunal, en la línea del TUP. Incluso en el caso del Reglamento 1151/2012 ${ }^{34}$, que contempla la creación de derechos que son la única modalidad de protección admisible en la Unión, de modo que no coexisten con títulos de carácter nacional, la tutela civil de los derechos tiene lugar mediante el ejercicio de acciones ante tribunales nacionales y no mediante la creación de una única jurisdicción con su propio tribunal.

16. Lo anterior no impide apreciar que un sistema eficaz de tutela de los eventuales títulos unitarios de derechos de autor que produzcan los mismos efectos en toda la Unión debería ir unido necesariamente a la adopción de disposiciones de competencia judicial internacional que complementaran a las previstas en el régimen general del Reglamento (UE) 1215/2012 o Reglamento Bruselas I bis (RBIbis) ${ }^{35}$. Como ilustra la experiencia del RMUE y del RDC (e incluso los arts. 71 bis a 71 quinquies del RBIbis con respecto al TUP), la adopción de normas especiales de competencia resultaría necesaria tanto para adaptar el marco actual a un contexto diferente de derechos de exclusiva cuyos efectos se extenderían al conjunto de la Unión, como para colmar las carencias derivadas del limitado ámbito de aplicación territorial de las reglas de competencia del RBIbis en virtud de lo dispuesto en su artículo $6^{36}$. No resultaría apropiada la remisión a las reglas nacionales de competencia, como hace el artículo 6 RBIbis, con respecto a litigios relativos a la tutela de derechos de alcance unitario. El Tribunal de Justicia ha puesto de relieve cómo los diferentes objetivos perseguidos por los reglamentos que crean título unitarios, de una parte, y por el RBIbis, de otra, condicionan las diferencias en la configuración e interpretación de sus respectivas reglas de competencia judicial internacional ${ }^{37}$.

17. Desde la perspectiva del Derecho aplicable, la creación de títulos europeos con un régimen normativo común fijado en un reglamento de la Unión reduciría significativamente los conflictos de leyes y la inseguridad jurídica en lo relativo a la normativa sustantiva aplicable en situaciones en las que se pretende la tutela transfronteriza, por ejemplo, al reclamar su protección frente a actividades de infracción en línea que producen efectos significativos en numerosos Estados miembros. En todo caso, las cuestiones de Derecho aplicable no desaparecerían por completo, pues en la línea de lo que sucede con respecto a los instrumentos que crean títulos unitarios en materia de marcas o diseños, resultará necesario establecer la legislación de qué Estado miembro es de aplicación en el caso concreto a las cuestiones no reguladas en el correspondiente instrumento ${ }^{38}$.

18. Más allá de estas consideraciones, de momento la creación de títulos unitarios en el ámbito de los derechos de autor y conexos constituye únicamente parte de una visión a largo plazo de difícil realización. Esa visión contrasta con la realidad de que en el seno de la Unión coexisten 27 -tras la retirada del Reino Unido- sistemas de tutela mediante derechos de exclusiva de alcance nacional, lo que, ob-

${ }^{34}$ Reglamento (UE) n 1151/2012, de 21 de noviembre de 2012, sobre los regímenes de calidad de los productos agrícolas y alimenticios, DO L 343, 14.12.2012, p. 1.

${ }_{35}$ Reglamento (UE) 1215/2012, de 12 de diciembre de 2012, relativo a la competencia judicial, el reconocimiento y la ejecución de resoluciones judiciales en materia civil y mercantil, DO L 351, 20.12.2012, p. 1.

${ }^{36} \mathrm{Vid}$. A. KuR, "Enforcement of Unitary Intellectual Property Rights: International Jurisdiction and Applicable Law", Journal of Intellectual Property Law \& Practice, vol. 10, 2015, pp. 468-480; y T.B. LARSEN, Intellectual Property Jurisdiction Strategies (Where to Litigate Unitary Rights vs National Rights in the EU), Cheltenham, Edward Elgar, 2017, apdos. 2.08-2.55.

${ }^{37}$ STJUE de 18 de mayo de 2017, Hummel Holding, C-617/15, EU:C:2017:390, apdos. 27 y 28. Vid. también STJUE de 5 de junio de 2014, Coty Germany, C-360/12, EU:C:2014:1318, apdos. 26 y 27; STJUE de 13 de julio de 2017, Bayerische Motoren Werke, C-433/16, EU:C:2017:550, apdo. 39; y STJUE de 5 de septiembre de 2019, AMS Neve, C-172/2018, EU:C:2019:674, apdos. 34-59.

${ }^{38}$ C. Heinze, 'Unitary intellectual property rights and private international law', J. Basedow, G. Rühl, F. Ferrari y P. De Miguel Asensio (eds.), Encyclopedia of Private International Law, Cheltenham, Edward Elgar, pp. ... cit., vol. 2, 2017, pp. 1796-1808. 
viamente, plantea dificultades específicas con respecto a la utilización transfronteriza de las obras en el seno de la Unión y la protección de los contenidos frente a eventuales infracciones en línea. En este contexto, resulta de interés centrar el análisis en valorar si existen alternativas más fácilmente viables que permitan contribuir a superar las dificultades que la actual fragmentación inherente a la coexistencia de títulos de derechos de autor nacionales suscita en relación con la tutela transfronteriza de tales derechos en el contexto del mercado único digital. Especial atención debe merecer la búsqueda de alternativas que hagan posible la adopción con base en una sola legislación de medidas frente a infracciones en línea con repercusión en todo o gran parte del mercado único. Una característica de los títulos unitarios es que las prohibiciones de los actos de infracción que se adoptan con base en ellos van referidas, en principio, a todo el territorio de la UE, sin perjuicio de que en ocasiones puedan establecerse ciertas restricciones ${ }^{39}$. Por el contrario, las medidas basadas en una legislación nacional sobre derechos de autor han de limitarse típicamente al territorio del Estado cuya legislación fundamenta la adopción de las medidas, debido al reducido alcance territorial de los derechos que atribuye.

19. Existe un creciente interés en superar los obstáculos que la fragmentación nacional de los sistemas de derechos de autor en la UE impone a la tutela y utilización de contenidos en el entorno digital. Esa fragmentación dificulta respecto de las actividades en Internet una tutela efectiva de los derechos, por ejemplo, al hacer imposible la adopción por el tribunal competente de medidas relativas al conjunto de la UE basadas en una única legislación. Asimismo, esa situación es fuente de incertidumbre para quienes utilizan contenidos, por ejemplo, en sitios de Internet, que pueden tener que considerar las legislaciones de todos los Estados miembros para verificar que lo hacen de manera legal ${ }^{40}$.

\section{Tutela transfronteriza de los derechos de autor}

\section{Fundamentos}

20. El ejercicio de acciones relativas a la protección de derechos sobre contenidos intelectuales respecto del territorio de varios (o incluso todos los) Estados miembros ante los tribunales de uno de ellos facilita la adopción de medidas (de prohibición, indemnizatorias...) referidas potencialmente al conjunto de la Unión. La posibilidad de que un tribunal de un Estado miembro adopte medidas relativas a la tutela de derechos de autor con respecto al territorio de varios Estados miembros o incluso de la Unión en su conjunto depende, en primer lugar, del alcance de su competencia judicial internacional. A este respecto, en el marco del RBIbis es claro que la regla de competencia exclusiva establecida en su artículo 24.4, que restringe la tutela transfronteriza ${ }^{41}$, va referida únicamente a los derechos de propiedad industrial sometidos a registro, de modo que no alcanza a litigios en materia de derechos de autor y derechos conexos ${ }^{42}$, cuya protección por el ordenamiento jurídico se produce de manera automática sin estar sometida a formalidades ${ }^{43}$.

21. En consecuencia, en el marco del RBIbis los tribunales de un Estado miembro al que las partes se han sometido (arts. 25 y 26), en el que se encuentra el domicilio del demandado (art. 4, en relación con los arts. 62 y 63) o en el que se localiza el origen del daño (art. 7.2) pueden llegar a conocer de demandas relativas a la tutela de derechos de autor y derechos conexos con respecto al territorio de varios o todos

${ }^{39}$ STJUE de 12 de abril 2011, DHL Express France, C-235/09, EU:C:2011:238, apdos. 39 a 48; y STJUE de 22 de septiembre de 2016, C-223/15, combit Software, EU:C:2016:719, apdos. 31 a 35.

${ }^{40}$ P.A. De Miguel Asensio, Derecho Privado de Internet, $5^{\text {a }}$ ed., 2015, Navarra, Civitas, pp. 643-862.

${ }^{41}$ Vid., v.gr., STJUE de 13 de julio de 2006, GAT, C-4/03, EU:C:2006:457; y STJUE de 13 de julio de 2006, Roche Nederland, C-539/03, EU:C:2006:458.

${ }^{42}$ Vid. D. Moura Vicente, A Tutela Internacional da Propiedade Intelectual, 2a ed., Coimbra, Almedina, 2019, pp. 424-430.

${ }^{43}$ Cuestión distinta y de limitada trascendencia práctica es si la competencia exclusiva en materia de validez de las inscripciones en registros públicos puede ser relevante en relación con registros de propiedad intelectual que sin eficacia constitutiva existen en Estados miembros. 
los Estados miembros de la UE (e incluso de terceros Estados). La competencia con ese alcance puede también fundamentarse en el artículo 8.1 RBIbis en los casos de pluralidad de demandados. El Tribunal de Justicia ha puesto de relieve que el ejercicio frente a varios demandados de acciones de infracción basadas en normativas nacionales de diferentes Estados miembros en materia de derechos de autor, en la medida en que esas legislaciones resulten esencialmente idénticas por la armonización europea, puede satisfacer la exigencia de identidad de las bases jurídicas de las acciones ejercitadas que constituye uno de los presupuestos para apreciar el riesgo de resoluciones inconciliables que requiere para su aplicación el fuero del artículo 8.1. ${ }^{44}$ Todos estos criterios de competencia operan con ese mismo alcance también cuando se pretende la adopción de medidas provisionales o cautelares (arts. 35 y 2 RBIbis).

\section{Correlación entre competencia judicial y territorialidad de la propiedad intelectual}

22. El artículo 7.2 RBIbis reviste especial importancia en relación con los litigios relativos a la tutela de derechos de autor y derechos conexos, pues típicamente la infracción de esos derechos constituye "materia delictual" a los efectos de hallarse comprendida en su supuesto de hecho. Conforme a esa disposición, se atribuye competencia a los tribunales del "lugar donde se hubiere producido o pudiere producirse el hecho dañoso". Al interpretar esta norma en caso de alegaciones de infracciones cometidas a través de Internet que pueden materializarse en numerosos lugares, el Tribunal de Justicia ha establecido que son competentes para conocer de las demandas por infracción de los derechos de autor y derechos afines: a) los tribunales lugar de origen del daño, que tendrán competencia con alcance general; y b) los tribunales de los diversos lugares de manifestación del daño, que solo serán competentes para conocer del daño causado a los derechos de autor y derechos conexos en el territorio de su respectivo Estado miembro ${ }^{45}$. La competencia basada en la localización de la manifestación del daño puede resultar especialmente atractiva para el titular de derechos en la medida en que puede ser la única vía para demandar ante los tribunales de su propio domicilio con respecto a actividades llevadas a cabo por infractores que actúan desde otros países.

23. Existe correlación entre el criterio de competencia basado en el lugar de manifestación del daño y el carácter territorial de los derechos de autor y los derechos afines. El fuero del lugar de manifestación del daño en relación con la vulneración de derechos de exclusiva de carácter territorial está limitado al territorio al que va referido el derecho supuestamente infringido ${ }^{46}$. Con respecto a la tutela de los derechos de autor, el Tribunal de Justicia ha puesto de relieve que los órganos jurisdiccionales del Estado miembro al que va referido el derecho de autor supuestamente infringido son los que se encuentran en mejor posición para valorar la eventual infracción del derecho y determinar la naturaleza del daño causado $^{47}$. Ahora bien, dos aspectos de la jurisprudencia del Tribunal de Justicia en este ámbito resultan controvertidos. Por una parte, destaca el debate acerca de si la mera accesibilidad de los contenidos infractores en un Estado miembro resulta suficiente para apreciar la materialización del daño a los efectos de fundar la competencia en el artículo 7.2 RBIbis. Por otra parte, se cuestiona el que en relación con las actividades en el entorno digital la interpretación actual del artículo 7.2 facilite atribuir una competencia fragmentada a los tribunales de un gran número de países.

24. Con respecto al primero de esos aspectos, el Tribunal de Justicia ha vinculado la improcedencia de valorar si existe o no vulneración del derecho de autor en la fase de examen de la competencia con el criterio de que el artículo 7.2 RBIbis atribuye en todo caso competencia a los tribunales del Estado a cuyo territorio van referidos los derechos patrimoniales supuestamente infringidos, en la medida en

\footnotetext{
${ }^{44}$ STJUE de 1 de diciembre de 2011, Painer, C-145/10, EU:C:2011:798, apdo. 82.

${ }^{45}$ P. De Miguel Asensio, Conflict of Laws and the Internet, Cheltenham, Edward Elgar, 2020, paras. 4.52-4.95.

${ }^{46}$ En relación con la infracción de marcas, vid. STJUE de 19 de abril de 2012, Wintersteiger, C-523/10, EU:C:2012:220, apdo. 29.

47 STJUE de 3 de octubre de 2013, Pinckney, C-170/12, EU:C:2013:635, apdo. 37.
} 
que es en su circunscripción territorial en la que puede materializarse el daño alegado. En virtud de ese planteamiento, la mera accesibilidad del sitio web supuestamente infractor en el territorio al que van referidos los derechos cuya protección se reclama se considera suficiente para localizar ahí el lugar de manifestación del daño a los efectos del artículo 7.2 RBIbis, correspondiendo al análisis sobre el fondo del asunto determinar si como consecuencia de la actividad de ese sitio de Internet existe o no infracción ${ }^{48}$. En la interpretación del Derecho material prevalece el criterio que para poder apreciar la existencia de infracción en un territorio es preciso que la actividad en cuestión produzca efectos significativos en el mismo, de modo que típicamente no basta con la mera accesibilidad en ese territorio de actividades llevadas a cabo en línea ${ }^{49}$.

25. Quienes tradicionalmente han rechazado que la mera accesibilidad deba ser suficiente a estos efectos, lo han hecho poniendo de relieve los riesgos -incluso de falta de previsibilidad- que puede implicar para el demandado en situaciones en las que su página web claramente no va dirigida (y no produce efectos relevantes) en el foro, habida cuenta del alcance potencialmente global de todos los sitios de Internet (dejando a un lado el eventual recurso a mecanismos de restricción, como los basados en herramientas de geolocalización). Se trata de un riesgo más intenso en principio en el caso de las pretendidas infracciones de derechos de marca y de competencia desleal, que en el caso de los derechos de autor. En particular en relación con estos últimos, sitios de Internet dirigidos a uno o varios mercados pueden producir efectos sustanciales en otros, desde los que acceden usuarios. En todo caso, en relación con los criterios de previsibilidad y buena administración de justicia en la aplicación de las reglas de competencia del RBIbis, cabe plantear si no hubiera sido adecuado que el Tribunal de Justicia requiriera la verificación de que en el caso concreto la accesibilidad del sitio web en el territorio para el que se reclama la protección permite apreciar que en el mismo se ha producido o puede producirse un daño a los efectos del artículo 7.2 RBIbis.

26. El que la difusión de contenidos protegidos por derechos de autor puede tener lugar a través de Internet en circunstancias en las que eventualmente se infrinjan derechos de un gran número de territorios ha sido una circunstancia clave para cuestionar si en esas situaciones debe rechazarse la posibilidad de atribuir competencia en virtud del artículo 7.2 RBIbis a los tribunales del lugar de materialización del daño, limitando la competencia basada en esa norma a los tribunales del Estado donde se haya producido el hecho causal ${ }^{50}$. Se trata de un planteamiento que no ha seguido el Tribunal de Justicia ${ }^{51}$. El criterio de materialización del daño resulta un componente esencial del artículo 7.2 RBIbis, incluso tratándose de la eventual infracción de derechos patrimoniales de autor mediante la difusión de contenidos a través de Internet. El lugar (o lugares) de materialización coincide típicamente con el país cuyos derechos son infringidos (o con cada uno de los países cuyos derechos son supuestamente infringidos), de modo que resultaría difícil aceptar que, por ejemplo, los tribunales del Estado miembro A no vayan a ser competentes de la eventual infracción de los derechos patrimoniales de autor en su territorio, en la medida en que la demanda tenga por objeto la violación de derechos en dicho Estado miembro, incluso si tal infracción es el resultado de la difusión de contenidos con alcance global a través de Internet.

27. Las dificultades para concretar los daños producidos en un concreto territorio como consecuencia de esa actividad difusa, así como las dificultades en relación con el alcance de las eventuales medidas de cesación de conductas son elementos tradicionalmente identificados como problemáticos en

\footnotetext{
${ }^{48}$ STJUE de 3 de octubre de 2013, Pinckney, C-170/12, EU:C:2013:635, apdo. 46; y STJUE de 22 de enero de 2015, Hej$d u k, \mathrm{C}-441 / 13, \mathrm{EU}: \mathrm{C}: 2015: 28$, apdo. 37.

${ }^{49} \mathrm{Vid}$. STJUE de 21 de junio de 2012, Donner, C-5/11, EU:C:2012:370, apdos. 27-28, con respecto a los derechos de autor; y STJUE de 18 de octubre de 2012, Football Dataco, C-173/11, EU:C:2012:642, apdo. 39, en el ámbito de las bases de datos. Asimismo, en relación con las marcas, vid. STJUE de 12 de julio de 2011, L'Oréal, C-324/09, EU:C:2011:474, apdo. 65.

${ }^{50}$ Conclusiones del AG Cruz Villalón de 11 de septiembre de 2014, Hejduk, C-441/13, EU:C:2014:221, apdos. 25 y 40; y conclusiones del AG Bobek de 13 de julio de 2017, Bolagsupplysningen, C-194/16, EU:C:2017:554, apdos. 79-80.

${ }^{51}$ Dejando al margen del análisis esos planteamiento de las conclusiones, vid. STJUE de 22 de enero de 2015, Hejduk, C-441/13, EU:C:2015:28; y STJUE de 17 de octubre de 2017, Bolagsupplysningen, C-194/16, EU:C:2017:766.
} 
este ámbito. Esa complejidad condicionará en su caso, por ejemplo, la configuración de las medidas de cesación por parte del tribunal competente. Tales dificultades, sin embargo, no parecen determinantes con carácter general para negar la posibilidad de atribuir competencia con base en el artículo 7.2 en aquellos casos en que quepa apreciar que se ha producido o puede producirse un daño en ese concreto territorio. El desarrollo de la tecnología, y en concreto el uso generalizado de mecanismos de geolocalización son claves en este contexto, en el que la compartimentación territorial de Internet es algo consustancial al funcionamiento y la explotación de los más variados servicios.

28. El alcance de la competencia basada en el lugar de materialización del daño se restringe a la infracción de los derechos de autor en el foro, lo que tendrá como consecuencia el limitado alcance de las de las medidas de cesación que puede adoptar un tribunal competente con base en ese criterio así como de los daños sobre los que puede pronunciarse. Desde el punto de vista práctico, la estricta limitación territorial de la competencia atribuida resulta un importante contrapeso a la facilidad con la que el artículo 7.2 permite atribuir competencia a los tribunales de los Estados miembros a cuyos respectivos territorios van referidos los derechos de autor supuestamente infringidos. La competencia limitada atribuida a los tribunales del lugar de manifestación del daño permite el ejercicio de acciones no solo en relación con la indemnización de los daños y perjuicios sufridos en ese territorio sino también relativas a la restricción de la difusión de la información en la medida en que vayan referidas solo a ese territorio ${ }^{52}$. De este modo, resulta posible la adopción de medidas que restringen el acceso a esa información desde el territorio del foro, como es el caso de las llamadas blocking injunctions. ${ }^{53}$ Esta fragmentación entre diversos Estados de la competencia se corresponde con el carácter nacional de los derechos de autor en el seno de la Unión Europea y con la importancia práctica de medidas como las órdenes de cesación referidas al territorio del foro, cuyo cumplimiento puede imponer el tribunal que las adopta -por ejemplo, por medio de los proveedores locales de acceso a Internet-, sin que resulte preciso el reconocimiento o ejecución en el extranjero.

29. La fragmentación a que conduce el fuero del lugar de la materialización del daño con respecto a muchas actividades realizadas a través de Internet no sólo afecta en realidad a la competencia, sino que en todo caso - es decir, cuando conozcan los tribunales del domicilio del demandado o los del lugar donde se haya producido el hecho causal- resulta determinante en el panorama actual para concretar la ley aplicable. Así, aunque del asunto conozca un único tribunal -y en ese plano no haya fragmentación- si su competencia no se limita a los daños causados en el foro (como puede suceder cuando se base en el fuero general del domicilio del demandado o en el del lugar del hecho causal) resultará preciso delimitar el concreto alcance de la infracción o los daños en cada territorio para establecer la(s) ley(es) aplicable(s) con base en el art. 8 Reglamento Roma II $^{54} \mathrm{y}$ su respectivo alcance (por lo tanto, para determinar si ha habido infracción en cada uno de esos territorios y cuáles son las consecuencias de la infracción en cada uno de ellos).

\section{Límites y condicionantes de la competencia de alcance global}

30. El fuero del domicilio del demandado (o de uno de los demandados con base en el art. 8.1 RBIbis) y el del lugar del origen del daño (art. 7.2 RBIbis) atribuyen competencia sin restricción territorial en litigios relativos a la tutela de derechos de autor y derechos afines. Esta circunstancia resulta determinante de las medidas susceptibles de ser adoptadas, si bien su configuración se halla condicionada por el carácter territorial de los derechos de autor y derechos conexos. Antes de abordar esa cuestión, resulta de interés

${ }^{52}$ Vid. R. Matulionyte, "Enforcing Copyright Infringements Online: In Search of Balanced Private Inter-national Law Rules", JIPITEC, vol. 6, 2015, 132-145, p. 139; y M. TrimBLE, “The Multiplicity of Copyright Laws on the Internet", Fordham Intell. Prop. Media \&Ent. L.J., Vol. XXV, 2015, pp. 339-405, p. 391.

${ }^{53}$ Vid., v.gr., L. Lundstedt, 'Putting Right Holders in the Centre: Bolagsupplysningen and Ilsjan (C-194/16): What Does It Mean for International Jurisdiction over Transborder Intellectual Property Infringement Disputes?’, IIC, vol. 49, 2018, pp. 1022-1047, pp. 1043-1044.

${ }^{54}$ Vid. D. Moura Vicente, A Tutela ... cit., pp. 348-358. 
hacer referencia a dos aspectos: la concreción del lugar del origen del daño a los efectos del artículo 7.2 RBIbis en este tipo de situaciones; y la valoración de si en relación con la tutela de los derechos de autor frente a actividades en línea cabe establecer algún criterio adicional de competencia de alcance general, como ha admitido la jurisprudencia del TJUE en relación con la tutela de derechos de la personalidad.

31. Con respecto a la primera de esas dos cuestiones, resulta de especial interés la sentencia del Tribunal de Justicia en el asunto Hejduk, en la que proyectó con respecto un litigio relativo a la infracción de derechos de autor como consecuencia de la difusión de fotografías en un sitio web, el criterio previamente establecido en su sentencia Wintersteiger en el ámbito de las marcas ${ }^{55}$. El Tribunal constató que el hecho que generaba una eventual vulneración de los derechos de autor consistía en la conducta del propietario del sitio web que difundía las imágenes, de modo que los actos u omisiones que podían constituir tal vulneración se localizaban en el lugar de la sede de la empresa supuestamente responsable, en la medida en que fue en ese lugar en el que la empresa tomó y ejecutó la decisión de poner en línea las fotografías en un determinado sitio de Internet ${ }^{56}$. En consecuencia, esa posibilidad presenta con frecuencia escasa relevancia práctica para el titular de los derechos, pues la competencia de los tribunales de ese lugar, y con ese mismo alcance general, puede fundamentarse normalmente con base en el fuero general del domicilio del demandado.

32. En lo relativo a si existe algún criterio adicional de competencia de alcance general con respecto a la tutela de los derechos de autor frente a actividades en línea, cabe partir de que el Tribunal de Justicia ha puesto de relieve en varias sentencias que su jurisprudencia eDate Advertising en materia de derechos de la personalidad no es aplicable a las reclamaciones relativas a derechos de propiedad industrial e intelectual ${ }^{57}$. Por su parte, en relación con los derechos morales de autor resulta relevante que el Tribunal de Justicia todavía no se ha pronunciado en demandas fundadas en su vulneración, por lo que respecto de los derechos morales cabe sostener que la cuestión puede resultar controvertida. La eventual aplicación de la jurisprudencia eDate Advertising a estas reclamaciones resultaría de importancia práctica en la medida en que facilitaría la reclamación por parte de la víctima (demandante) ante los tribunales de su propio domicilio por el conjunto del daño. En la práctica española presenta un singular interés el Auto de 12 de marzo de 2015 de la sección 15 de la Aud. Prov. de Barcelona ${ }^{58}$, si bien en relación con la aplicación de las normas de competencia internacional de fuente interna.

33. Dicho Auto va referido a una demanda de una autora española contra una empresa qatarí y el Estado de Qatar relativa a "que las demandadas habían vulnerado los derechos morales de divulgación, paternidad e integridad de la actora sobre su obra al encargar la construcción del referido modelo de farola" [según parece en China y Turquía] "y colocarlo en una de las calles de Doha" [Qatar] (ap. 1 del Auto), procediendo a solicitar la retirada de las farolas en Doha así como una indemnización en concepto de daños morales. La Aud. Prov. de Barcelona concluye que los tribunales españoles tienen competencia judicial internacional para conocer de la demanda, básicamente por considerar razonable aplicar el artículo 22.3 LOPJ -actual art. 22 qinquies.b)-, que exige que el hecho dañoso se haya producido en territorio español, en sintonía con la doctrina del Tribunal de Justicia en su sentencia eDate Advertising relativa a derechos de la personalidad. Una valoración crítica del Auto no impide apreciar que resulta razonable el enfoque adoptado por la Audiencia en lo relativo a que la norma del artículo 22.3 LOPJ debe ser interpretada en sintonía con la norma del artículo 7.2 RBIbis, por lo que es apropiado acudir a la jurisprudencia del Tribunal de Justicia relativa al fuero del lugar del daño. Ahora bien, precisamente en la sentencia $e D a-$ te Advertising la dificultad de localización derivaba de que las actividades infractoras objeto de los litigios

${ }^{55}$ STJUE de 19 de abril de 2012, Wintersteiger, C-523/10, EU:C:2012:220, apdo. 34.

${ }^{56}$ STJUE de 22 de enero de 2015, Hejduk, C-441/13, EU:C:2015:28, apdos. 25 y 26.

${ }^{57} \mathrm{Vid}$. STJUE de 19 de abril de 2012, Wintersteiger, C-523/10, EU:C:2012:220, apdos. 24-25; y STJUE de 3 de octubre de 2013, Pinckney, C-170/12, EU:C:2013:635, apdos- 36-37 y 43.

${ }^{58}$ Auto Aud. Prov. de Barcelona (Sección 15ª num. 32/2015 de 12 marzo, ES:APB:2015:1256A. Con posterioridad, vid. Sent. Aud. Prov. de Barcelona (Sección 15ª) 512/2020 de 6 de marzo, ES:APB:2020:2644.” 
principales se llevaban a cabo a través de Internet y el Tribunal de Justicia dejó claro de manera reiterada que la solución específica que permite a la víctima reclamar ante los tribunales de su centro de intereses sólo resulta de aplicación cuando la actividad supuestamente infractora se produce a través de Internet ${ }^{59}$, lo que no sucedía en el asunto sobre el que se pronuncia la Audiencia Provincial. La territorialidad de los derechos morales de autor constituye un elemento diferenciador de gran importancia con respecto a lo que es propio de los derechos de la personalidad ${ }^{60}$, pues en relación con los derechos morales de autor, en principio, no será determinante para establecer la ley aplicable el artículo $10.9 \mathrm{Cc}$ sino el art. 8 RRII ${ }^{61}$.

34. Que los tribunales de un Estado miembro tengan competencia con alcance general en relación con un litigio relativo a la vulneración de derechos de autor es un presupuesto necesario para la adopción de medidas con potencial repercusión global, como la supresión de información de Internet. Ahora bien, ese presupuesto por sí solo no justifica la adopción de tales medidas, que habrá de ser valorado en función de la normativa aplicable ${ }^{62}$. En el caso de litigios relativos a la infracción de derechos de propiedad intelectual, junto al alcance de la competencia judicial internacional del tribunal, otro condicionante esencial de la extensión espacial de las medidas es el carácter territorial de los derechos supuestamente vulnerados. Al tratarse de derechos de exclusiva de carácter territorial, el alcance de las medidas debe en principio estar limitado por el ámbito territorial de los derechos que resultan menoscabados. El alcance de la prohibición debería corresponderse en principio con el territorio de los ordenamientos respecto de los que se ha establecido la eventual infracción, en virtud de la correspondiente ley(es) del país(es) para el que se reclama la protección.

35. Se trata de un aspecto al que el Tribunal de Justicia ha tenido ocasión de prestar especial atención en relación con la infracción de marcas de la Unión. Aspecto fundamental de la doctrina que deriva de la sentencia DHL Express es que "el alcance territorial de una prohibición de seguir cometiendo actos de violación o de intento de violación de una marca comunitaria... viene determinado tanto por la competencia territorial del tribunal de marcas comunitarias que dicta dicha prohibición como por el ámbito territorial del derecho exclusivo del titular de una marca comunitaria que resulta menoscabado por la violación o el intento de violación" ${ }^{63}$. Por ello, en el caso concreto de las marcas de la Unión resulta determinante de la respuesta tanto el carácter unitario de toda marca de la UE -que va referida al conjunto del territorio de la UE- como que el alcance de la competencia de los tribunales de marcas fundada en los apartados 1 a 4 del artículo 125 RMUE comprende los actos de violación cometidos o que intenten cometerse en cualquier Estado miembro (a diferencia de lo que sucede cuando la competencia se funda en el artículo 125.5, ya que el art. 126. 2 limita su alcance a "pronunciarse sobre los hechos cometidos o que intenten cometerse en el territorio del Estado miembro en que radique ese tribunal". En la sentencia DHL Express el Tribunal de Justicia concluyó que la competencia del órgano judicial que conocía del asunto principal puede extenderse a todo el territorio de la Unión y que para garantizar la protección uniforme de la marca comunitaria en todo el territorio de la UE "la prohibición de continuar cometiendo actos de violación o de intento de violación de la marca comunitaria dictada por un tribunal de marcas comunitarias competente debe extenderse, en principio, a todo el territorio de la Unión"

\footnotetext{
${ }^{59}$ STJUE de 25 de octubre de 2011, eDate Advertising, C-509/09 y C-161/10, EU:C:2011:685, apdos. 45 y ss.

${ }^{60}$ Acerca de la aplicación de las mismas reglas de competencia a la infracción de derechos patrimoniales y derechos morales de autor, en la práctica de la Cour de Cassation francesa, vid. Cass. 1re civ., 22 de enero de 2014, n 11-28.822.

${ }^{61}$ Con respecto a la aplicación de la lex loci protectionis a los derechos morales de autor, vid. J. BASEDow, "Article 3:102: Lex protectionis", European Max Planck Group on Conflict of Laws in Intellectual Property (ed), Conflict... cit., para. 3:102.C06; y P.E. GeLLER, "International Copyright: The Introduction", § 3[1][b][iii][B], http://www.internationalcopyrightguide.com/, publicado en L. BentLY (ed.), International Copyright Law and Practice, (LexisNexis, 2017). Por el contrario, acerca de la eventual consideración de los derechos morales de autor también como derechos de la personalidad a efectos de determinar la regla de conflicto aplicable, vid. L. LundSTEDT, Territoriality in Intellectual Property Law, Stockholm University, 2016, p. 425.

${ }^{62} \mathrm{Vid}$., aunque en sectores diferentes a los derechos de autor, STJUE de 17 de octubre de 2017, Bolagsupplysningen, C-194/16, EU:C:2017:766; STJUE de 24 de septiembre de 2019, C-507/17, Google (Portée territoriale du déréférencement), EU:C:2019:772; y STJUE de 3 de octubre de 2019, Glawischnig-Piesczek, C-18/18, EU:C:2019:821. En particular, vid. conclusiones del AG Szpunar de 4 de junio de 2019, Glawischnig-Piesczek, C-18/18, EU:C:2019:458, apdo. 86.

${ }^{63}$ STJUE de 12 de abril de 2011, DHL Express, C-235/09, EU:C:2011:238, apdo. 33.
} 
(apdo. 44). Es decir, en ese tipo de situaciones las medidas de prohibición irán referidas típicamente al conjunto de la Unión, en línea con el carácter unitario y la extensión territorial del derecho de exclusiva infringido. También en la sentencia Nintendo el Tribunal de Justicia constató que en el caso de los derechos unitarios el derecho objeto de infracción se extiende al conjunto del territorio de la Unión, de modo que la competencia basada en el artículo 8.1 RBIbis - fuero de la pluralidad de demandados- no es una competencia limitada a una parte del territorio de la UE, por lo que el tribunal nacional puede adoptar medidas cuyo alcance vaya referido al conjunto de la Unión ${ }^{64}$.

36. Se trata de una interpretación que facilita el logro del objetivo del RMUE de proteger eficazmente las marcas de la Unión en todo el territorio de la Unión. Este planteamiento refuerza la posibilidad de obtener ante un único tribunal la tutela para el conjunto del territorio de la Unión de los derechos unitarios. Por el contrario, la situación es diferente en relación con la tutela de los derechos de autor y derechos conexos en el seno de la UE, ya que en esta materia la tutela va referida a un haz de derechos nacionales, de modo que, en principio, para adoptar medidas relativas al territorio de varios Estados miembros debe estarse a lo dispuesto en la legislación sobre propiedad intelectual de cada uno de ellos.

\section{Fundamento y retos del criterio lex loci protectionis}

37. Vinculado al carácter territorial de los derechos de autor, el criterio lex loci protectionis se traduce en que la ley aplicable a la tutela (e infracción) de derechos de autor y derechos afines sea la del país para el que se reclama la protección. El artículo 8.1 del Reglamento 864/2007 (Roma II) lo formula como regla de conflicto bilateral: "La ley aplicable a la obligación extracontractual que se derive de una infracción de un derecho de propiedad intelectual será la del país para cuyo territorio se reclama la protección”. Con respecto a la fundamentación de esta norma, el considerando 26 del Preámbulo del Reglamento, se limita a señalar que en materia de infracciones de los derechos de propiedad intelectual "conviene preservar el principio lex loci protectionis que se reconoce universalmente".

38. En el caso de infracciones de derechos de autor cometidas a través de Internet o de otros medios con potencial repercusión mundial el criterio lex loci protectionis conduce a la aplicación cumulativa, aunque de manera distributiva, de las leyes de varios, potencialmente muchos, países. Ello es debido a que esa regla de conflicto determina que la ley de cada país es aplicable a la protección de los derechos de propiedad intelectual en su propio territorio, de manera que cuando las actividades de infracción afectan a una pluralidad de países la legislación de cada uno de ellos es aplicable con respecto a las infracciones acaecidas en su propio territorio. Tratándose de la utilización en línea de obras o prestaciones protegidas, el criterio lex loci protectionis lleva en principio a localizar el uso de la obra o prestación en cada Estado desde el que los usuarios acceden a la obra o prestación protegida. En la jurisprudencia del Tribunal de Justicia resulta especialmente significativa su sentencia Football Dataco ${ }^{65}$, en el sentido de que los actos de utilización en línea de obras y otras prestación se consideran localizados en el Estado miembro donde se encuentra quien recibe o accede a la información, en particular cuando existan indicios de la intención de quien pone la información a disposición de dirigirse a los miembros del público establecidos en este Estado miembro ${ }^{66}$.

${ }^{64}$ STJUE de 27 de septiembre de 2017, Nintendo, C-24/16 y C-25/16, EU:C:2017:724, apdos. 61 a 66. Ahora bien, la jurisprudencia del Tribunal de Justicia ha puesto también de relieve que el carácter unitario de las marcas de la Unión y el que produzcan los mismos efectos en todo su territorio no impiden que en determinadas circunstancias las medidas de prohibición que puedan adoptarse en caso de infracción de tales marcas excluyan parte del territorio de la Unión, de modo que no prohíban el uso por parte del infractor demandado en las zonas que quedan al margen de la medida. Cuando no existe riesgo de confusión en una parte de la Unión, no se puede prohibir el comercio lícito unido al uso del signo en cuestión en esa parte de la Unión (STJUE de 22 de septiembre de 2016, combit Software, C-223/15, EU:C:2016:719, apdo. 32).

${ }^{65}$ STJUE de 18 de octubre de 2012, Football Dataco, C-173/11, EU:C:2012:642, apdo. 39.

${ }^{66}$ Asimismo, vid. STJUE de 12 de julio de 2011, L'Oréal, C-324/09, EU:C:2011:474, apdo. 65; y STJUE de 21 de junio de 2012, Donner, C-5/11, EU:C:2012:370, apdos. 27-28. 
39. Ese cúmulo distributivo que conduce a la aplicación de una pluralidad de ordenamientos se corresponde con el carácter territorial y la configuración tradicional de estos derechos, pero dificulta de manera muy significativa el enjuiciamiento de las reclamaciones sobre infracciones de una pluralidad de países ${ }^{67}$, de manera que la posibilidad de tramitar ante los tribunales de un país demandas relativas a la infracción por el demandado de derechos de una pluralidad de países resulta en la práctica una tarea de gran complejidad, por la dificultad de probar y aplicar el contenido de un elevado número de ordenamientos extranjeros ${ }^{68}$. Desde la perspectiva del mercado único digital, ese planteamiento excluye la posibilidad de lograr la tutela de los derechos sobre contenidos culturales en el conjunto de la UE con base en una única legislación.

\section{Mercado interior y aplicación de un régimen unitario}

\section{El criterio de origen en el entorno digital}

40. Al interpretar el significado del criterio de origen o mercado interior (art. 3) de la Directiva 2000/31 sobre el comercio electrónico, el Tribunal de Justicia ha establecido que no impone una solución conflictual sino que lo que exige es la no aplicación de las normas de la ley designada por la regla de conflicto que restrinjan dentro del ámbito coordinado la libertad del prestador establecido en otro Estado miembro $^{69}$. Ahora bien, la Directiva prevé que ese criterio no opera en el ámbito de los derechos de autor y derechos afines, lo que se corresponde con el respeto del carácter territorial (nacional) de estos derechos. Tal como se dispone en el Anexo y en el artículo 3.3 de la Directiva 2000/31 el criterio de origen no se aplica, entre otros, al ámbito de los derechos de autor y derechos afines. Asimismo, el artículo 1.5 del Reglamento (UE) 2018/302 que impide el bloqueo geográfico ${ }^{70}$ establece que sus disposiciones no afectan a las normas aplicables en materia de derechos de autor, al tiempo que prevé que la prohibición a los comerciantes de aplicar condiciones generales de acceso diferentes a sus bienes o servicios por motivos relacionados con la nacionalidad o con el lugar de residencia o de establecimiento del cliente no resulta en principio de aplicación a los comerciantes que presten servicios electrónicos cuya característica principal sea el suministro de acceso a obras protegidas por derechos de autor o a otras prestaciones protegidas y la utilización de esas obras y prestaciones (art. 4.1.b) ${ }^{71}$.

41. Antes del desarrollo de Internet, el interés por evitar la aplicación cumulativa de múltiples legislaciones a la difusión de contenidos a través de medios con impacto en una pluralidad de países se reflejó ya en una opción limitada por el criterio de origen en la Directiva 93/83/CEE sobre derechos de autor y derechos afines en el ámbito de la radiodifusión vía satélite y de la distribución por cable. Conforme a su artículo 1.2.a), la comunicación al público vía satélite se considera producida únicamente en el Estado miembro en que las señales portadoras se introduzcan en una cadena ininterrumpida de comunicación $^{72}$. En los instrumentos más recientes adoptados en el contexto del mercado único digital se observa una tendencia, limitada a aspectos puntuales, a superar la fragmentación nacional de los dere-

${ }^{67}$ Vid., v.gr., J.C. Ginsburg, "The Private International Law of Copyright in an Era of Technological Change”, $R$. des $C$., 1998, t. 273, pp. 243-405; y P.E. GelLeR, "From Patchwork to Network: Strategies for International Intellectual Property in Flux", Vand. J.T.L., vol. 31, 1998, pp. 553-574, pp. 556-558.

${ }^{68}$ J. DreXL, "Internationales...", cit., paras. 335 y 344.

${ }^{69}$ STJUE de 25 de octubre de 2011, eDate Advertising, C-509/09 y C-161/10, EU:C:2011:685, apdo. 61.

${ }^{70}$ Reglamento (UE) 2018/302 de 28 de febrero de 2018 sobre medidas destinadas a impedir el bloqueo geográfico injustificado y otras formas de discriminación por razón de la nacionalidad, del lugar de residencia o del lugar de establecimiento de los clientes en el mercado interior y por el que se modifican los Reglamentos (CE) n. ${ }^{\circ}$ 2006/2004 y (UE) 2017/2394 y la Directiva 2009/22/CE, DO L 60I de 2.3.2018, p. 1.

${ }^{71} \mathrm{Vid}$. T.E. Synodinou, “Geoblocking in EU Copyright Law: Challenges and Perspectives”, GRUR International, vol. 69, 2020, pp. 136-150.

${ }^{72}$ Acerca de la interpretación de qué supuestos quedan comprendidos en ese artículo y reafirmando al margen de ellos el principio de territorialidad, vid. STJCE de 14 de julio de 2005, Lagardère, C-192/04, EU:C:2005:475. 
chos de autor en el seno de la UE mediante la localización en un Estado miembro de ciertas actividades aunque vayan (potencialmente) dirigidas a varios (todos los) Estados miembros.

42. Complemento esencial de la armonización en el ámbito de la UE en materia de servicios de comunicación audiovisual -tanto emisiones televisivas como servicios de comunicación audiovisual a petición sobre la base de un catálogo de programas- es el establecimiento del llamado principio del país de origen. En virtud de este criterio, el artículo 3 de la Directiva 2010/13/UE -modificada por la Directiva 2018/1808- de servicios de comunicación audiovisual impone a los Estados miembros la obligación de garantizar la libertad de recepción y no obstaculizar las retransmisiones en su territorio de los servicios de comunicación audiovisual procedentes de otros Estados miembros por motivos inherentes a los ámbitos coordinados por dicha Directiva ${ }^{73}$. Únicamente cumpliendo las exigentes condiciones impuestas en su apartado 2, los Estados miembros pueden establecer excepciones. A diferencia de la Directiva sobre el comercio electrónico, la relativa a los servicios de comunicación audiovisual tiene "ámbitos coordinados" mucho más concretos, pues están limitados en principio a las materias objeto de armonización por esta Directiva. Entre esas materias se incluyen, por ejemplo, las medidas tendentes a garantizar que los servicios de comunicación audiovisual no contengan incitaciones al odio por razón de raza, sexo, religión o nacionalidad. Por el contrario, el régimen de los derechos de autor y derechos afines queda al margen de su ámbito coordinado y en principio también de la aplicación del criterio de origen. En todo caso, puede resultar útil hacer referencia a la interpretación por el TJUE del criterio de origen de esta Directiva, en cuya jurisprudencia reciente destaca la sentencia Baltic Media Alliance ${ }^{74}$.

43. Un aspecto controvertido en el litigio principal era si el criterio de origen resultaba realmente aplicable, en la medida en que únicamente se benefician de él los servicios de comunicación audiovisual procedentes de otros Estados miembros. Si bien se trataba de programas producidos en un Estado tercero, como Rusia, su difusión la llevaba a cabo una sociedad registrada en el Reino Unido con licencia de las autoridades británicas. Si dicha entidad podía ser considerada un "prestador de servicios de comunicación" establecido en el Reino Unido con respecto a los programas de la cadena rusa controvertidos, se beneficiaría del criterio de origen, estando sometida al control de las autoridades del Reino Unido. Aunque el Tribunal de Justicia concluye que el origen de los programas (en concreto el que procedan de un tercer Estado) no es un elemento relevante a esos, los apartados 38 a 51 de la sentencia ponen de relieve que la determinación de si una sociedad registrada en un Estado miembro se beneficia de la consideración de "prestador de servicios de comunicación" establecido en dicho Estado puede requerir un complejo análisis. Resulta una exigencia ineludible que la sociedad en cuestión ostente la responsabilidad editorial sobre la elección del contenido audiovisual, de modo que sea ella quien seleccione y organice cronológicamente los programas de la cadena, sin que a esos efectos resulte decisivo que la sociedad en cuestión haya obtenido licencia en un Estado miembro. Además, es preciso que el prestador se considere establecido en un Estado miembro en los términos de la Directiva, lo que exige que tenga su sede central en el Estado miembro en cuestión y que además se tomen en él las decisiones editoriales sobre el servicio de comunicación audiovisual, de acuerdo con el artículo 2.3.a) de la Directiva. El Tribunal de Justicia considera criterios relevantes para concretar el establecimiento elementos como el domicilio social, el lugar de toma de las decisiones editoriales respecto de sus servicios de comunicación audiovisual, así como el lugar en el que trabaja el personal que realiza las actividades de esos servicios. Si el resultado de proyectar al caso concreto el análisis anterior es que la sociedad registrada en un Estado miembro no reúne los requisitos para ser considerada a esos efectos un "prestador de servicios de comunicación" establecido en un Estado miembro, la consecuencia es que no se beneficia del criterio de origen, de modo que los Estados miembros no están obligados a garantizar la libertad de recepción y no

${ }^{73}$ En lo relativo al concepto de servicio de comunicación audiovisual y su proyección sobre los sitios de Internet vid. STJUE de 21 de octubre de 2015, New Media Online, C-347/14, EU:C:2015:709; y STJUE de 21 de febrero de 2018, Peugeot Deutschland, C-132/17, EU:C:2018:85.

${ }^{74}$ STJUE de 4 de julio de 2019, Baltic Media Alliance, C-622/17, EU:C:2019:566. 
obstaculizar las retransmisiones de ese canal en su territorio, por lo que sus posibilidades de control del canal en cuestión no quedan limitadas por lo previsto en la Directiva 2010/13/UE.

44. La sentencia Baltic Media Alliance también abordó el tratamiento de emisiones por un prestador establecido en un Estado miembro pero dirigidas exclusivamente al territorio de otro Estado miembro. De la sentencia se desprende que el régimen específico previsto por la Directiva 2010/13/UE prevalece en este ámbito sobre la jurisprudencia del Tribunal de Justicia relativa al artículo 56 TFUE, de modo que para la adopción de medidas frente a ese tipo de prestadores establecidos en otro Estado miembro debe estarse al gravoso y complejo mecanismo previsto en los apartados 2 a 5 del artículo 4 de la Directiva ${ }^{75}$. En el diferente marco de la Directiva 2000/31 sobre el comercio electrónico, su considerando 57 destaca expresamente que la jurisprudencia del Tribunal de Justicia "siempre ha sostenido que un Estado miembro conserva el derecho de adoptar medidas contra un prestador de servicios establecido en otro Estado miembro, cuya actividad se dirige principalmente o en su totalidad hacia el territorio del primer Estado miembro, cuando dicho establecimiento se haya realizado con la intención de evadir la legislación que se hubiera aplicado al prestador de servicios en caso de que se hubiera establecido en el territorio del primer Estado miembro". Aunque la Directiva 2000/31 regula también las condiciones bajo las que los Estados miembros pueden tomar medidas para restringir la libre prestación de servicios de la sociedad de la información, básicamente en los apartados 4 y 5 de su artículo $3^{76}$, no contemplan, a diferencia del artículo 4 de la Directiva 2010/13/UE, específicamente las situaciones en las que un prestador ofrece un servicio dirigido total o principalmente al territorio del Estado miembro que adopta las medidas.

\section{Portabilidad transfronteriza de contenidos en línea}

45. El Reglamento (UE) $2017 / 1128^{77}$ establece medidas para que una práctica habitual, en virtud de la cual la prestación de servicios de contenidos en línea -música, juegos, películas, programas de entretenimiento o acontecimientos deportivos.... queda limitada al territorio del Estado de la residencia habitual del abonado, no impida el acceso y utilización de tales contenidos por parte de los abonados residentes en un Estado miembro cuando se encuentran temporalmente en otro Estado miembro. La limitación territorial del acceso por el consumidor a los contenidos en línea resulta en principio una exigencia derivada de que en los contratos de licencia habitualmente los prestadores de servicios de contenidos en línea se comprometen con los titulares de derechos a impedir que sus abonados accedan a los servicios y los utilicen fuera del territorio al que se extiende la licencia otorgada al prestador. De este modo, resulta habitual que con ese propósito el prestador impida el acceso a sus servicios desde direcciones IP situadas fuera del territorio al que va referida la licencia, típicamente el del Estado miembro de residencia habitual del abonado. El Reglamento (UE) 2017/1128 no pretende terminar con la compartimentación territorial de los mercados, como consecuencia del limitado alcance de las licencias, sino tan solo establecer un régimen especial cuando se trata de abonados que se desplazan temporalmente a un Estado miembro distinto al de su residencia habitual. En concreto, su artículo 3.1 impone a los prestadores de este tipo de servicios la obligación de hacer posible "que un abonado que se encuentre temporalmente en un Estado miembro acceda al servicio de contenidos en línea y lo utilice del mismo modo que en su Estado miembro de residencia".

46. Para lograr ese fin el legislador de la Unión utiliza básicamente en relación con los derechos de autor el mecanismo consistente en la localización ficticia de los actos de acceso y utilización de los contenidos realizados durante esos desplazamientos temporales. Como establece su artículo 4: "Se con-

${ }^{75}$ Ibid., apdo. 54; asimismo, vid. los apdos 49 y 50 de las conclusiones del AG Saugmandsgaard Øe de 28 de febrero de 2019, Baltic Media Alliance, C-622/17, EU:C:2019:154.

${ }^{76} \mathrm{Vid}$. STJUE de 19 de diciembre de 2019, Airbnb Ireland, C-390/18, EU:C:2019:1112, apdos. 83-85 y 96.

${ }^{77}$ Reglamento (UE) 2017/1128 relativo a la portabilidad transfronteriza de los servicios de contenidos en línea en el mercado interior, DO L 168, 30.6.2017, p. 1. 
siderará que la prestación de un servicio de contenidos en línea en virtud del presente Reglamento a un abonado que se encuentre temporalmente en un Estado miembro, así como el acceso al servicio y su uso por parte de dicho abonado, se produce únicamente en su Estado miembro de residencia." En la medida en que esa actividad aunque se lleve a cabo en otro Estado miembro se considera localizada en el Estado miembro de residencia del abonado, el acceso a los contenidos puede proporcionarse por el prestador de servicios sin adquirir los correspondientes derechos en el Estado miembro en el que el abonado se encuentra temporalmente. En los términos del considerando 24 del Reglamento: “...los correspondientes actos de reproducción, comunicación al público y puesta a disposición de las obras y otras prestaciones protegidas, así como los actos de extracción o reutilización en relación con bases de datos protegidas por derechos sui generis, que se producen cuando se presta el servicio a un abonado que se encuentra temporalmente en un Estado miembro que no sea aquel en que reside, deben entenderse producidos en el Estado miembro de residencia del abonado", de modo que se consideran realizados "al amparo de las respectivas licencias de los titulares de derechos afectados aplicables en el Estado miembro de residencia del abonado".

47. La localización se contempla únicamente a esos efectos, por lo que el tratamiento específico tiene un alcance muy limitado. Además, como aclara el considerando 16, los servicios en línea que no sean servicios de comunicación audiovisual en el sentido de la Directiva 2010/13/UE y que utilicen obras de manera puramente auxiliar, como es habitual en sitios web, no son objeto de este Reglamento. Tampoco es aplicable el Reglamento al acceso por los consumidores a servicios de contenidos en línea prestados en un Estado miembro que no sea su Estado miembro de residencia. No resulta de aplicación obligatoria a los prestadores de servicios de contenidos en línea prestados sin que medie un pago en dinero. Por otra parte, los abonados que se benefician de este régimen han de ser en todo caso consumidores residentes en un Estado Miembro.

48. Para asegurar que los abonados que se encuentren temporalmente en un Estado miembro que no sea el de su residencia puedan continuar utilizando los servicios, el artículo 7 del Reglamento incluye una disposición declarando inaplicable toda disposición contractual que prohíba o limite dicha portabilidad. Se trata de una previsión de especial interés en relación con las posibles restricciones territoriales incluidas en los contratos entre los prestadores de servicios de contenidos en línea y los titulares de derechos, así como entre dichos prestadores y sus abonados. Además, el artículo 7.2 incorpora una disposición aclaratoria no prevista en la Propuesta inicial de la Comisión, según la cual el Reglamento se aplicará con independencia de la normativa aplicable a los contratos mencionados. En consecuencia, aunque la ley aplicable, por ejemplo, a un contrato entre el titular de derechos y el prestador de servicios de contenido en línea sea, de acuerdo con lo previsto en el artículo 3 del Reglamento Roma I, la de California, ello no impedirá que sobre el contenido del Derecho californiano prevalezca lo dispuesto en este Reglamento, en particular que resulte inaplicable toda restricción territorial contenida en el contrato con el titular de derechos y que resulte incompatible con la obligación impuesta al prestador de servicios por el artículo 3 del Reglamento (UE) 2017/1128. La introducción de una previsión expresa como la del artículo 7.2 parece avalar el criterio de que el nuevo Reglamento constituye una norma internacionalmente imperativa a los efectos del artículo 9.2 del Reglamento Roma I, aunque también podría alcanzarse un resultado similar sobre la base de que la norma resulta aplicable en virtud del criterio lex loci protectionis (art. 10.4 Cc y art. 8 RR II) en la medida en que se trate de contratos relativos a la transmisión de derechos de Estados miembros de la UE, al integrarse el Reglamento en sus respectivos ordenamientos. Con independencia del enfoque elegido, la norma sólo resultará de imperativa aplicación en la medida en que el contrato se proyecte sobre abonados residentes en un Estado miembro y respecto de la utilización cuando se encuentren temporalmente en otro Estado miembro, de modo, que por ejemplo, la norma no debe resultar de aplicación en la medida en que el contrato entre el titular de derechos y el prestador de servicios abarque también la explotación de derechos en terceros Estados. 


\section{Directiva (UE) 2019/790 sobre los derechos de autor en el mercado único digital}

49. La dimensión internacional tiene especial relevancia en la reforma de la normativa sobre derechos de autor en el entorno digital llevada a cabo por la Directiva (UE) 2019/790, como destaca su primer artículo. En concreto, su artículo 1.1 hace referencia a que su normativa tiene "especialmente en cuenta los usos digitales y transfronterizos de los contenidos digitales". Con respecto a los usos transfronterizo es relevante que la adopción de directivas sobre derechos de autor y derechos afines en el seno de la Unión se traduce, como es bien conocido, en la aproximación de las legislaciones nacionales, pero no contempla la creación de títulos unitarios para el conjunto de la Unión. Un primer conjunto de normas de la Directiva (UE) 2019/790 establece excepciones y limitaciones a derechos de autor y derechos afines respecto de ciertos usos de obras y otras prestaciones en relación con la "minería de textos y datos" (definida en su artículo 2.2 como "toda técnica analítica automatizada destinada a analizar textos y datos en formato digital a fin de generar información que incluye, sin carácter exhaustivo, pautas, tendencias o correlaciones"), las actividades pedagógicas y la conservación del patrimonio cultural. Se trata de los artículos 3 a 7 de la Directiva, orientados a mejorar la deficiente armonización de las excepciones y limitaciones a los derechos de autor y derechos afines, uno de los ámbitos en los que las carencias del régimen de la Unión, en especial en relación con el artículo 5 de la Directiva (CE) 2001/29, resultaban más notables.

50. En lo relativo a las excepciones y limitaciones, la dimensión transfronteriza es objeto de especial atención en la Directiva (UE) 2019/790 con respecto a la utilización de obras y otras prestaciones en actividades pedagógicas, lo que reviste especial importancia en un contexto de expansión de la enseñanza en línea ${ }^{78}$. Se trata de una materia en la que la nueva Directiva introduce, en particular, una excepción o limitación para proporcionar seguridad jurídica a los centros de enseñanza cuando utilicen obras u otras prestaciones en actividades pedagógicas digitales. La excepción o limitación tiene carácter obligatorio y va referida, conforme a su artículo 5.1, al uso digital de obras y otras prestaciones únicamente a efectos de ilustración con fines educativos, en la medida en que ello esté justificado por la finalidad no comercial perseguida y cuando dicho uso cumpla dos condiciones: a) tenga lugar bajo la responsabilidad de un centro de enseñanza, en sus locales o en otros lugares, o a través de un entorno electrónico seguro al que solo puedan acceder los estudiantes y su personal docente, y b) vaya acompañado de la indicación de la fuente, con inclusión del nombre del autor, salvo que ello resulte imposible. Pese al carácter obligatorio de la excepción, subsistirán ciertas diferencias en las legislaciones de los Estados miembros. El artículo 5.2 de la Directiva (UE) 2019/790 permite que en determinadas circunstancias los Estados pueden prever que la excepción no se aplique con respecto a determinados usos o tipos de obras u otras prestaciones, en particular cuando estén fácilmente disponibles en el mercado acuerdos de licencia adecuados que autoricen esos actos y adaptados a las necesidades de los centros de enseñanza. Además, los Estados tienen libertad para especificar de manera equilibrada la proporción de una obra u otra prestación que puede utilizarse únicamente a efectos de ilustración con fines educativos (considerando 21). En definitiva, la armonización no evita que subsistan diferencias en el alcance de esta excepción o limitación según las legislaciones nacionales

51. En ese contexto, la disposición clave para facilitar el desarrollo de las actividades educativas digitales transfronterizas en el seno de la Unión en relación con esta excepción o limitación aparece recogida en el apartado 3 del artículo 5, que establece: "Se considerará que el uso de obras y otras prestaciones únicamente a efectos de ilustración con fines educativos a través de entornos electrónicos seguros que se haga en cumplimiento de las disposiciones de Derecho nacional adoptadas en virtud del presente artículo, únicamente tiene lugar en el Estado miembro en que está establecido el centro de enseñanza." Para evitar la aplicación de ese cúmulo de leyes al que conduce el criterio lex loci protectonis, y la carga que su cumplimiento plantea para los centros de enseñanza en lo que tiene que ver con las posibles

${ }^{78}$ M. TRIMBLe, "COVID-19 and Transnational Issues in Copyright and Related Rights", IIC, vol. 51, 2020, pp. 407-410, destacando la importancia de la aproximación de las normas de Derecho internacional privado. 
diferencias respecto de la licitud del empleo de las obras y prestaciones con fines educativos a través de entornos electrónicos seguros, así como su interacción con la obtención de licencias que autorizan usos de ese tipo, el artículo 5.3 establece la ficción de que el uso a efectos de ilustración con fines educativos a través de entornos electrónicos seguros se considera que únicamente tiene lugar en el Estado miembro de establecimiento del centro de enseñanza. La transposición de esta norma en las legislaciones nacionales de los Estados miembros implica que en la medida en que cada una de esas legislaciones sea aplicable en virtud del criterio lex loci protectionis, la previsión de que el acto se localiza únicamente en el Estado miembro de establecimiento del centro de enseñanza supone que basta para su uso lícito en los demás Estados miembros con que el uso de las obras o prestaciones satisfaga los requisitos para su utilización lícita en ese concreto Estado miembro. Obviamente, el criterio de origen opera únicamente en relación con el uso de las obras y prestaciones en Estados miembros, de modo que no es aplicable con respecto a los usos de las obras en terceros Estados, por ejemplo en aquellas situaciones en las que el centro de enseñanza dirija también su actividad educativa a terceros Estados.

52. Las consideraciones anteriores resultan aplicables mutatis mutandis con respecto al otro supuesto de empleo de esta técnica basada en el criterio de origen que establece la Directiva (UE) 2019/790. En concreto, la localización ficticia del uso de ciertas obras y prestaciones en el Estado miembro de origen aparece prevista también en su artículo 9.2 en relación con la excepción o limitación que su artículo 8.2 impone para facilitar la puesta a disposición de las instituciones responsables del patrimonio cultural, con fines no comerciales, de obras u otras prestaciones fuera del circuito comercial que se encuentren en su colección permanente. En concreto, en virtud del artículo 9.2, los usos de obras y otras prestaciones al amparo de esa excepción o limitación, se considera que se producen solamente en el Estado miembro en el que está establecida la institución responsable del patrimonio cultural de que se trate.

\section{Transmisiones en línea de organismos de radiodifusión}

53. Junto a determinadas normas relativas al ejercicio de los derechos de retransmisión de los programas de radio y televisión, la Directiva (UE) 2019/789 tiene por objeto establecer el tratamiento de lo que denomina servicios accesorios en línea de los organismos de radiodifusión. El régimen que incorpora en relación con esta última materia reviste gran importancia de cara a facilitar la difusión transfronteriza en toda la Unión de ciertos programas de radio y televisión de los organismos de radiodifusión. El carácter territorial de los derechos de autor y derechos conexos constituye en principio un obstáculo a la difusión por medio de Internet más allá de las fronteras nacionales de programas de radio y televisión, en la medida en que estos programas incorporan contenidos objeto de tales derechos, como obras musicales o audiovisuales, respecto de los que los organismos de radiodifusión o quienes retransmiten los programas únicamente han adquirido derechos para territorios concretos, típicamente en el ámbito europeo de carácter estatal. Para ofrecer sus servicios en línea a través de las fronteras, los organismos de radiodifusión necesitan tener los derechos necesarios con respecto a las obras y otras prestaciones protegidas en todos los territorios pertinentes, lo que aumenta la complejidad de la obtención de estos derechos. Con el objetivo de facilitar la posibilidad de difundir esos programas a través de Internet en el conjunto de la Unión, la Directiva (UE) 2019/789 dispone la extensión respecto de ciertos servicios en línea del principio del país de origen a partir del modelo establecido para la radiodifusión por satélite en la Directiva 93/83/CEE, antes reseñada, cuyas disposiciones no son de aplicación a la prestación de servicios en línea.

54. La definición de "servicio accesorio en línea" de su artículo 2.1) resulta determinante del alcance de las normas de la Directiva sobre el particular. En concreto, esa categoría aparece definida como: "un servicio en línea consistente en el suministro al público por un organismo de radiodifusión, o bajo su control y responsabilidad, de programas de radio o televisión simultáneamente con su emisión por parte del organismo de radiodifusión, o posteriormente a esa emisión durante un período de tiempo definido, así como de cualquier material que sea accesorio a tal emisión". En consecuencia, comprende tanto el suministro de esos contenidos en streaming (de manera lineal simultánea a la emisión) como los 
servicios en diferido, mediante la posibilidad de acceder a los programas previamente emitidos por el organismo de radiodifusión dentro de un período de tiempo definido posterior a la emisión, a programas de radio y televisión. Además, el considerando 8 aclara que se incluyen también los servicios que dan acceso a materiales que amplían los programas de radio y televisión emitidos por el organismo de radiodifusión, en particular mediante previsualización, extensión, suplementación o revisión del contenido del programa de que se trate. En realidad, la definición del artículo 2.1) puede resultar excesivamente restrictiva, en la medida en que no parece incluir las situaciones en las que los organismos permiten el acceso al programa íntegro en línea antes (o con independencia) de su emisión, así como cuando el organismo permite el acceso en línea con posterioridad a la emisión pero sin en principio fijar un periodo de tiempo definido, por ejemplo, cuando los programas se integran en un archivo (que integra un conjunto ordenado de ellos) en el que se encuentran accesibles en línea sin fijar un límite temporal.

55. Como ha quedado apuntado, el criterio del país de origen es el mecanismo al que recurre la Directiva (UE) 2019/789 para que el ejercicio de los derechos de autor y derechos afines no dificulte excesivamente la prestación de servicios accesorios en línea transfronterizos por parte de los organismos de radiodifusión en el ámbito de la UE. El recurso al principio del país de origen supone una excepción muy relevante pero puntual a la aplicación del criterio lex loci protectionis. La aplicación de la ley del país para el que se reclama la protección (a cuyo territorio va referido el acto de explotación) y que conduce típicamente a la necesidad de respetar las legislaciones de los diversos países en los que se contempla la explotación de la obra continúa siendo el criterio básico, derivado del carácter territorial de los derechos, incluso en el contexto de la prestación de servicios de la sociedad de la información en el mercado interior. Se trata de una situación coherente con la circunstancia ya reseñada de que el anexo de la Directiva 2000/31 sobre el comercio electrónico dejó los derechos de autor y los derechos afines -habida cuenta de su carácter territorial- al margen del criterio de origen, que su artículo 3 establece en relación con los servicios de la sociedad de la información.

56. La excepción al criterio lex loci protectionis que introduce la Directiva (UE) 2019/789 se apoya en la ficción de que determinados actos de explotación de una obra, a efectos del ejercicio de los derechos de autor y derechos afines, se producen únicamente en el Estado miembro en el que el organismo de radiodifusión tiene su establecimiento principal, como recoge su artículo 3.1, inspirado en el artículo 1.2.b) de la Directiva 93/83/CEE, si bien en ésta para localizar el Estado de origen hace referencia al Estado miembro en que se introduzcan las señales portadoras de programa en una cadena ininterrumpida de comunicación que vaya al satélite y desde éste a la tierra. Por su parte, en la nueva Directiva el país de origen se hace coincidir con el Estado miembro en el que el organismo de radiodifusión tiene su establecimiento principal. Aunque el principio de origen con respecto a los servicios accesorios en línea va referido a los programas de radio y de televisión, en el caso de estos últimos solo alcanza a los programas de noticias y de actualidad, así como a las producciones realizadas por organismo de radiodifusión utilizando sus propios recursos, sin incluir en ningún caso los acontecimientos deportivos, habida cuenta de que con frecuencia las licencias relativas a obras audiovisuales y acontecimientos deportivos son licencias territoriales exclusivas.

57. La ficción de que los actos de comunicación al público y de puesta a disposición de las obras se producen únicamente en el Estado miembro del establecimiento principal determina que para la explotación de la obra en el conjunto de la Unión basta en el ámbito en el que opera el criterio del país de origen con la adquisición por parte del organismo de radiodifusión de los derechos para ese país. Ahora bien, en la fijación del importe del pago de los derechos habrá de tenerse en cuenta el público que en otros Estados miembros acceda al servicio, al tiempo que resulta posible limitar la explotación de los derechos a ciertos métodos técnicos de transmisión o versiones lingüísticas.

58. En lo relativo a la interacción entre el principio del país del origen en la nueva Directiva y el criterio general lex loci protectionis en materia de tutela de la propiedad intelectual, debe destacarse que en la Directiva la localización en el país de origen se limita a los actos relevantes para los derechos de 
autor a efectos del ejercicio de los derechos, como es el caso de la obtención de licencias. Como ponía claramente de relieve la Propuesta de Reglamento de 2016 en la que se encuentra el origen de la nueva Directiva, el país de origen no afecta a la localización de los actos relevantes para los derechos de autor cuando no se hayan obtenido los derechos (es decir, en el caso de transmisiones no autorizadas) ${ }^{79}$. Además, el principio del país de origen no resulta de aplicación a subsiguientes comunicaciones al público, puestas a disposición o reproducciones de las obras o prestaciones protegidas incluidas en el servicio accesorio en línea (considerando 9 de la Directiva).

59. En consecuencia, respecto de los aspectos no cubiertos por el criterio del país de origen continúa siendo determinante la lex loci protectionis, de acuerdo con lo dispuesto principalmente en el artículo 8 del Reglamento Roma II, que conduce, como ha quedado ya señalado a la aplicación de cada uno de los Estados para los que se reclama la protección del derecho ${ }^{80}$, es decir dónde se localizan los supuestos actos de infracción en atención a la ubicación de quienes acceden a los contenidos infractores ${ }^{81}$. Por otra parte, tampoco el criterio de determinación del país de origen en la nueva Directiva resulta directamente aplicable para apreciar el Estado de origen del daño -sin perjuicio de que en la práctica frecuentemente coincidirán- al aplicar en el ámbito de la infracción de derechos de propiedad intelectual el fuero especial en la materia del artículo 7.2 del Reglamento Bruselas I bis, como refleja la jurisprudencia del Tribunal de Justicia relativa a la localización del "hecho causal" a los efectos de atribuir competencia internacional ${ }^{82}$.

\section{Perspectivas de futuro}

60. Estos avances muestran una tendencia a recurrir puntualmente al criterio de origen como mecanismo para superar algunos de los obstáculos que la fragmentación a nivel nacional de los derechos de autor plantea en el marco del mercado único digital. En la medida en que el objetivo de establecer títulos unitarios en el ámbito de los derechos de autor y derechos conexos se manifieste como irrealizable por lo menos en un plazo razonable, una alternativa para superar las principales carencias derivadas de la actual fragmentación con respecto a las actividades desarrolladas por Internet, que, aunque no exenta de dificultades, podría merecer más atención, es combinar el desarrollo de la armonización con la introducción de un criterio basado en la aplicación de la ley del Estado miembro de origen con respecto a la determinación del contenido y la infracción de los derechos de autor en todos los Estados miembros en lo relativo a las transmisiones por Internet. Con un grado de distorsión menor que la implantación de títulos unitarios, la adaptación del criterio de origen podría favorecer la seguridad jurídica y facilitar la tutela y explotación en el conjunto de la Unión de los derechos.

61. La expansión del criterio de origen sería coherente con los principios del mercado interior y el progresivo desarrollo de la legislación sobre derechos de autor y derechos conexos en la Unión ${ }^{83}$. Con respecto a la supresión de obstáculos a la difusión de contenidos en línea en el seno de la Unión, cabe recordar que la exigencia de que en virtud del artículo 3 de la Directiva 2000/31 el prestador de un ser-

${ }^{79}$ Propuesta de Reglamento por el que se establecen las normas sobre el ejercicio de los derechos de autor y determinados derechos afines a los derechos de autor aplicables a determinadas transmisiones en línea de los organismos de radiodifusión y a las retransmisiones de programas de radio y televisión, $\operatorname{COM(2016)~} 594$ final, de 14 de septiembre de 2016, p. 4, donde se afirma: "el país de origen no afecta a la localización de los actos relevantes para los derechos de autor cuando no se hayan obtenido los derechos (es decir, en el caso de transmisiones no autorizadas)"

${ }^{80}$ Vid., v.gr., T. Kono y P. JuRcys, “General Report”. T. Kono (ed.), Intellectual Property and Private International Law (Comparative Perspectives), Oxford, Hart, 2012, pp. 1-216, p. 153.

${ }^{81}$ Vid. STJUE de 12 de julio de 2011, L'Oréal, C-324/09, EU:C:2011:474, apdo. 65; STJUE de 21 de junio de 2012, Donner, C-5/11, EU:C:2012:370, apdos. 27-28; y STJUE de 18 de octubre de 2012, Football Dataco, C-173/11, EU:C:2012:642, apdo. 39.

${ }^{82}$ STJUE de 19 de abril de 2012, Wintersteiger, C-523/10, EU:C:2012:220, apdo. 34; y STJUE de 22 de enero de 2015, Hejduk, C-441/13, EU:C:2015:28, apdos. 25 y 26

${ }^{83}$ Vid. A. Ohly, "Choice of Law in the Digital Environment - Problems and Possible Solutions", J. DreXL y A. Kur (eds.), Intellectual Property and Private International Law- Heading for the Future, 2005, Oxford, Hart, pp. 241-256, 253-254. 
vicio de comercio electrónico no esté sujeto a requisitos más estrictos que los previstos por el Derecho material en vigor en el Estado miembro de establecimiento de dicho prestador fue proclamada por el Tribunal de Justicia en relación con litigios relativos a la eventual vulneración de derechos de la personalidad como consecuencia de la difusión de contenidos supuestamente difamatorios en línea ${ }^{84}$. Aunque se trata de una materia que no va referida a derechos de exclusiva de carácter territorial, constituye un ámbito que no ha sido objeto de regulación en el seno de la UE y sobre el que no existe normas comunes como es el relativo a los derechos de la personalidad. A diferencia de otros derechos de exclusiva territoriales, como los derechos de propiedad industrial, sometidos a registro, los derechos de autor y derechos conexos son en principio objeto de reconocimiento automático en todos los Estados miembros sin formalidad alguna. En todo caso, no cabe perder de vista que la fragmentación a nivel nacional de los derechos de autor implica que su titularidad y facultades de explotación puedan ser diferentes según los Estados miembros, lo que plantea dificultades de cara a la implantación del criterio del país de origen. La expansión del criterio de origen debería ir unido a una profundización de la armonización de las legislaciones sobre derecho de autor en el seno de la Unión ${ }^{85}$, ámbito territorial al que habría de restringirse la aplicación del criterio de origen, de conformidad con la situación característica del mercado interior. Ese reforzamiento de la armonización, en particular en lo relativo a las excepciones y limitaciones, sería necesario para asegurar el alto nivel de protección de estos derechos que es uno de los objetivos básicos de la Unión en este ámbito, así como para evitar posibles conductas oportunistas.

62. Un mayor recurso al criterio de origen con respecto a la utilización en línea de contenidos protegidos por derechos de autor en el mercado interior requeriría ciertas adaptaciones ${ }^{86}$. En lo que respecta a la concreción del Estado miembro de origen el enfoque de la Directiva (UE) 2019/789 y de las normas que establecen el criterio de origen de la Directiva (UE) 2019/790 constituye un precedente muy relevante, que además en las situaciones típicas conduce al ordenamiento de un Estado miembro cuyos tribunales tendrían competencia para conocer con alcance general -en virtud de los arts. 4 y 7.2 Reglamento Bruselas I bis-, lo que facilitaría la adopción de medidas para la tutela de derechos en el conjunto de la Unión con base en la ley del foro. Otras cuestiones que deberían ser valoradas es si puede resultar adecuado establecer un criterio de localización secundario respecto de prestadores establecidos en terceros Estados ${ }^{87}$, en caso de que se considerara que, habida cuenta de los peculiares intereses presentes en estas situaciones, procede recurrir a la legislación de un único Estado miembro con respecto a la utilización en la Unión de contenidos cuyos titulares no están establecidos en un Estado miembro. También sería oportuno valorar la introducción de excepciones al criterio de origen, por ejemplo, en relación con actividades de difusión de contenidos que se dirigen principal o exclusivamente a algún Estado miembro distinto del de origen. Con respecto a la adquisición de licencias e importe de los derechos para la difusión en línea más allá del Estado miembro de origen el enfoque de la Directiva (UE) 2019/789 sería un precedente a tener muy en cuenta. Por último, en lo relativo a la compatibilidad del criterio de origen con la regla lex loci protectionis, en la medida en que el criterio de origen se base en una localización ficticia en un único Estado miembro de la puesta a disposición en línea respecto de todos los Estados miembros que se incorpore en sus respectivas legislaciones materiales, la aplicación de la ley de origen sería consecuencia de la remisión particular contenida en la ley de cada Estado miembro para el que se reclama la protección.

\footnotetext{
${ }^{84}$ STJUE de 25 de octubre de 2011, eDate Advertising, C-509/09 y C-161/10, EU:C:2011:685, apdo. 68.

${ }^{85} \mathrm{Vid}$. M. LeISTNER, "Comments: The Rome II Regulation Proposal and its Relation to the European Country-of-Origin Principle”, J. DreXl y A. Kur (eds.), Intellectual... cit., pp. 177-199, pp. 193-194; y P.B. Hugenholtz, "The Future of Copyright Law in the Digital Single Market: extending the Satellite \& Cable Directive to content services online", Bonn, 2015, https://www.jura.uni-bonn.de/fileadmin/Fachbereich_Rechtswissenschaft/Einrichtungen/Sonstige/Zentrum_fuer_Europaeisches_Wirtschaftsrecht/Schriftenreihe/Heft_216.pdf, p. 15.

${ }^{86}$ P. De Miguel Asensio, Conflict..., cit., paras. 4.142-4.151.

${ }^{87}$ Centre for European Policy Studies, "Copyright in the EU Digital Single Market", Report of the CEPS Digital Forum by G. Mazziotti, Bruselas, 2013, https://www.ceps.eu/ceps-publications/copyright-eu-digital-single-market/, pp. 63-64.
} 